\title{
DEFINING YIELD STRENGTH FOR NONPRESTRESSED REINFORCING STEEL
}

\section{By Conrad Paulson, Jeffrey M. Rautenberg, Scott K. Graham, and David Darwin}

Analytical strengths of reinforced concrete beams and columns based on reinforcing steel stressstrain curves with and without a sharp yield plateau and the nonlinear stress-strain behavior of concrete are compared with strengths calculated in accordance with the ACI Building Code to determine the feasibility of using the $0.2 \%$ offset method to define the yield strength of reinforcing steel. Comparisons include steel yield strengths of 60,000 and 80,000 psi (420 and $550 \mathrm{MPa}$ ) and concrete compressive strengths of 5,000, 8,000, and 12,000 psi (34, 55, and 83 $\mathrm{MPa}$ ). For beams with reinforcement ratios below three-quarters of the balanced ratio, the stressstrain curves based on the $0.2 \%$ offset method produce analytical strengths greater than or equal to those corresponding to the provisions of the ACI Code. For columns with total reinforcement ratios of 1 or $2 \%$, the lowest ratio of analytical to Code-calculated strength for reinforcement with yield strength defined based the $0.2 \%$ offset method is $97 \%$. The ratio drops with increasing reinforcement ratio, with the lowest value, 93\%, occurring at total reinforcement ratios of 6 to 8\%. The lower ratios occur for combinations of moment and axial load where the strength reduction factor is 0.65 for tied columns and 0.75 for spirally reinforced columns, thus maintaining an adequate margin of safety. The results justify use of the $0.2 \%$ offset method to define the yield strength of reinforcing steel.

Keywords: beams, building codes, columns, reinforced concrete, reinforcing steel, specifications, strain, stress, strength 


\section{INTRODUCTION}

Generations of structural engineers have proportioned reinforced concrete beams and columns using Whitney's (1937) model, which represents reinforcing steel as an elastic-perfectly plastic material in both tension and compression. First adopted as an alternative method of design in the 1956 ACI Building Code (ACI Committee 318 1956) and, ultimately, as the main method of design in the 1971 ACI Building Code (ACI Committee 318 1971), Whitney’s model, with its assumption of elastic-perfectly plastic steel, along with an equivalent stress block to represent the nonlinear stress-strain response of concrete in compression, is the standard for the design of reinforced concrete sections in the U.S. and in many other countries. The assumption of elastic-perfectly plastic behavior for steel, based on a sharply yielding material was, at the time Whitney developed his model, highly realistic and reflected in reinforcing steel specifications (ASTM A15-35). Over the years, however, methods of producing steel and the

strength of the reinforcement have changed, so that Grade 40 (yield strength $f_{y}=40,000$ psi, 280 MPa) reinforcement, with its classic, sharply-yielding stress-strain behavior, which was commonly used 50 years ago, now represents only a small portion of the reinforcing steel market.

For many years, Grade $60(420)\left(f_{y}=60,000 \mathrm{psi}, 420 \mathrm{MPa}\right)$ reinforcement has been standard for reinforced concrete construction in the U.S., with Grade 75 (520) and, more recently, Grade 80 (550) being available for general use, and Grade 100 (690) being permitted for specific applications (ACI Committee 318 2014). Like the lower-strength steels, much of the higher-strength reinforcement exhibits sharply yielding behavior, like that shown in Fig. 1a. An important fraction of steel now on the market, however, does not exhibit a sharp yield point, but 
rather what is referred to as a roundhouse $(\mathrm{RH})$ stress-strain curve, such as illustrated in Fig. 1b, or gradual strain hardening, as shown in Fig. 1c. ${ }^{1}$

If reinforcing steel exhibits a well-defined yield point, ASTM specifications (ASTM A615-14, A706-14, A996-14a) permit yield strength to be determined using the halt-of-the-force method, in which an increasing force is applied to the tensile test specimen at the uniform rate and the load is recorded at which the force hesitates, as represented by Fig. 1a.

For reinforcing steel that does not exhibit a well-defined yield point, the yield strength has historically been determined as the stress achieved at a given elongation under load (EUL), as illustrated in Fig. 1c. Since 1976, ASTM specifications have required the yield strength of reinforcing steel without a well-defined yield point be based on EUL values of $0.35 \%$ or $0.5 \%$ (ASTM 615-76a), with a value of 0.5\% EUL applied for Grade 40 and sometimes Grade 60 (420), and more recently 0.35\% EUL for Grade 60 (420) and higher. Between 1971 and 2008, the ACI Code had no elongation requirements for Grades 40 and 60 reinforcement but applied a 0.35\% EUL requirement to Grades 75 and 80 (520 and 550).

At the same time that the reinforcing steel industry was implementing the EUL yield measurement criteria just described, much of the rest of the steel industry adopted an alternate method for establishing yield strength known as the offset method (OM) in which yield strength is taken as the stress at which a material exhibits a specified limiting deviation from proportionality of stress to strain. To determine yield strength by the offset method, it is necessary to obtain a stress-strain curve with distinct initial modulus elasticity. On a stress-strain diagram, such as shown in Fig. 1b, strain $O m$, equal to the specified value of the offset, is used to draw line $m n$ parallel to the initial modulus line $O A$ to locate the point $r$, the intersection of $m n$

\footnotetext{
${ }^{1}$ Based on test results from approximately 200 samples tested by WJE laboratories between 2003 and 2013, this fraction is thought to be on the order of $5 \%$ of the total volume of reinforcing steel produced in the U.S.
} 
with the stress-strain curve. The corresponding stress $R_{y}$ is defined as the yield strength. An offset of $0.2 \%$ has been used for many years for most steel products (other than concrete reinforcing steel) in the U.S.

\section{RESEARCH SIGNIFICANCE}

In 2009, the $0.2 \%$ offset method became the sole method for establishing the yield point in ASTM specifications for reinforcing steels that were not sharply yielding (ASTM A615-09, A706-09). Feedback from ACI Committee 318, however, resulted in the additional requirement that Grade 60 (420) and higher strength reinforcement must also meet the specified yield strength at 0.35 EUL (ASTM A615-09b, A706-09b) - a requirement that was felt to be largely untenable by the reinforcing steel industry. With the presumptive wider application of high-strength reinforcing steels (and accompanying nonlinear stress-strain behavior) and the potential for adoption in the 2014 ACI Code (ACI Committee 318 2014), research to evaluate the safety of fully converting to the $0.2 \%$ offset method $(0.2 \% \mathrm{OM})$ was undertaken. The results of that study, reported in this paper, served as the justification for the adoption of the $0.2 \%$ offset method in ACI 318-14 and all ASTM reinforcing bar standards (ASTM A615-14, A706-14, A955-14, A996-14a, A1035-14). Use of the 0.2\% offset method has simplified the ASTM specifications for reinforcing bars and brought the specifications in line with those used in the rest of the steel industry.

\section{METHODOLOGY}

The objective of the research was to assess the influence of stress-strain curve shape and the method of determining yield strength of reinforcing steel on the computed strength of reinforced concrete sections. This was accomplished by analyzing a range of beam and column cross sections and comparing the calculated strengths with (1) nominal strengths calculated 
following the provisions of ACI 318, (2) analytical strengths based on reinforcing steel with a realistic elastic-plastic-strain-hardening stress-strain curve similar to that of a material with a sharp yielding behavior, and (3) the code-calculated design strengths (capacity-reduction factor times nominal strength, $\phi \times$ nominal).

\section{Yield Strengths used for Analysis}

In this study, consideration was limited to reinforcing steel strengths that are currently permitted by ACI 318 for main reinforcement, that is, specified yield strengths ranging from 40,000 to 80,000 psi (280 and 550 MPa). From this group, Grades 60 and 80 (420 and 550) were selected for study based on the reasoning that these grades are manufactured under both ASTM A615 and ASTM A706, that Grade 60 (420) is the most commonly specified reinforcing steel, and that Grade 80 (550) represents the upper limit of specified yield strength permitted by ACI 318 for longitudinal nonprestressed reinforcement in beams and columns. Grade 40 steel was not included because it nearly always has a sharply yielding stress-strain curve, while Grade 75 (520) steel was not included because its performance is bracketed by Grades 60 and 80 (420 and $550)$.

In addition to straight reinforcing bars with grades in the 40 to 80 (280 and 550) range, ACI 318-14 also permits the use of stainless steel bars and wire, bars that are coiled immediately after rolling, and carbon steel wire as longitudinal nonprestressed reinforcement. Specifications for these products employ minimum specified yield strengths in the range of 60,000 to 80,000 psi (420 and $550 \mathrm{MPa}$ ). Coiled bars exhibit reduced initial moduli of elasticity, and thus, the effect of a reduced initial modulus was also included in the study. 


\section{Yield Measurement Methods}

In the study, both elongation under load (EUL) and the offset method (OM) were used to define yield strength. Because the values were standard for many years in ASTM specifications, EUL at a strain of $0.5 \%$ was used for Grade 60 (420) reinforcement and EUL at a strain of $0.35 \%$ was used for Grade 80 (550) reinforcement. In addition to the industry-adopted offset of $0.2 \%$ strain, an offset of $0.1 \%$ strain was also evaluated for both Grades 60 and 80 (420 and 550) reinforcement to provide a more complete picture of member performance as a function of offset. Historically, the $0.35 \%$ EUL strain requirement was selected by ACI Committee $318^{2}$ as being equivalent to the strain at an offset of $0.1 \%$ for $f_{y}$ of 75,000 psi.

\section{PARAMETRIC STUDY}

\section{Member Cross Sections and Materials Strengths}

Both beams and columns were used to determine the effect of stress-strain curve shape and the method of defining yield strength on calculated member capacity for reinforcing steel yield strengths of 60,000 and 80,000 psi (420 and $550 \mathrm{MPa}$ ). The beams (Fig. 2a) had concrete strengths of 5,000 and 8,000 psi (34 and $55 \mathrm{MPa}$ ). Flexural reinforcement ratios $\rho$ ranging from 0 to $6 \%$ were used to cover both tension-controlled (reinforcement yields) to compressioncontrol (reinforcement remains elastic) beams. The results for beams with a balanced reinforcement ratio $\rho_{b}$ (simultaneous yielding of steel and crushing of concrete) are specifically identified.

Square and rectangular (width $=1 / 2$ depth) columns, as shown in Fig. $2 \mathrm{~b}$ and $\mathrm{c}$, respectively, with reinforcement ratios based on the gross area of the column $\rho_{g}$ ranging from 1 to $8 \%$, the range permitted by ACI 318, were analyzed. Concrete strengths of 5,000, 8,000, and

\footnotetext{
${ }^{2}$ Report of Ad Hoc Group on Reinforcement, ACI Committee 318 on Standard Building Code, draft report, March 8, 1967, final report, April 10, 1967, unpublished.
} 
12,000 psi (34, 55, and $83 \mathrm{MPa}$ ) were used, along with a value of the ratio of the dimension of the column core to the dimension of the gross section $\gamma=0.8$. The two higher concrete strengths are representative of higher-strength concretes as used in practice. Most practical columns have reinforcement ratios $\rho_{g}$ between 1 and $2 \%$. Columns with $\rho_{g}$ of $4 \%$ or larger are normally considered to be heavily reinforced and, thus, less economical. The full range of reinforcement ratios, however, was used to fully ground the results. Rectangular columns with $\rho_{g}=1$ and $2 \%$, a compressive strength of 5,000 psi (34.4 MPa), and $\gamma=0.6$, as shown in Fig. 2d, were also analyzed.

\section{Reinforcement Stress-Strain Relationships}

The analytical stress-strain curves used in the study were selected to match those observed in practice for both straight and coiled reinforcing steel. Figure 3 illustrates representative stress-strain curves. As shown in the figure, five representations were considered: CODE, which is an idealized elastic-perfectly plastic stress-strain relationship without strain hardening; EPSH (elastic-plastic with strain hardening) with a significant length to the yield plateau followed by strain hardening; RKSH (rounded knee with strain hardening) with an initially elastic with a "rounded knee” stress-strain curve followed by a yield plateau, followed by strain hardening; GYSH (gradually yielding with strain hardening) with an initially elastic curve with strain hardening that has a nearly constant slope once yielding has begun; and RH 29, RH 22, and RH 21 (roundhouse), representing an initially elastic curve followed by a curvilinear transition to continuous yielding. The two-digit numerical suffix following RH represents the initial tangent modulus for the elastic portion in units of $10^{6}$ psi, with RH 22 and RH 21 representing coiled reinforcement, which upon straightening has residual stresses through the cross section causing one side of the reinforcing bar to yield before the other. 
For the analytical investigation, the relationships shown in Fig. 3 were narrowed. Considering that the EPSH relationship provides an upper bound and various RH relationships provide lower bounds, the RKSH and GYSH relationships were not included in the study.

\section{Normalized Relationships}

Based on the general shapes of actual stress-strain curves, individual "normalized" relationships were developed for use in the analytical strength calculations. The normalized stress-strain curves, described next, were selected to develop exactly the specified yield strength when yield is measured according to each of the measurement methods.

CODE. The CODE stress-strain relationship is implicitly normalized and in accord with assumptions included in ACI 318, with an initial elastic modulus of $29 \times 10^{6}$ psi (200 GPa) at strains less than the yield strength and perfectly plastic with a stress equal to $f_{y}$ for strains beyond yield. The CODE relationship does not include strain hardening.

$E P S H$. The EPSH stress-strain relationship has a sharp yield at $f_{y}$ and includes strain hardening behavior. The initial elastic modulus is $29 \times 10^{6} \mathrm{psi}$ (200 GPa) followed by a perfectly plastic yield plateau at $f_{y}$, followed by strain hardening beginning at a strain of $1.0 \%$ following the parabolic relationship of Eq. (1).

$$
f_{s}=f_{u}-\left(f_{u}-f_{y}\right)\left(\frac{\varepsilon_{s u}-\varepsilon}{\varepsilon_{s u}-\varepsilon_{s h}}\right)
$$

where $\varepsilon=$ strain in the reinforcement; $f_{s}=$ stress in the reinforcement; $f_{u}=$ specified tensile strength [90,000 psi (620 MPa) for Grade 60 (420), 100,000 psi (690 MPa) for Grade 80 (550)]; $f_{y}=$ specified yield strength [60,000 or 80,000 psi (420 or $\left.\left.550 \mathrm{MPa}\right)\right]$; $\varepsilon_{s u}=$ strain at development of tensile strength [taken to be $9 \%$ for Grade 60 (420), 6\% for Grade 80 (550)]; and $\varepsilon_{s h}=$ strain at onset of strain hardening (taken to be 1.0\%). 
$R H$. The normalized relationships for the RH curves are represented using the RambergOsgood (1943) relationship, Eq. (2).

$$
\varepsilon=\frac{f_{s}}{E}+\alpha \frac{f_{y}}{E}\left(\frac{f_{s}}{f_{y}}\right)^{n}
$$

where $E=$ modulus of elasticity; and $\alpha$ and $n=$ parameters that depend on the desired shape of the stress-strain curve. For each grade and type of steel, a representative sampling of actual stress-strain curves was plotted along with the Ramberg-Osgood equation, for example as shown in Fig. 4 for coiled Grade 60 (420) reinforcement. The parameter $\alpha$ is selected so that the stressstrain curve develops the specified value of $f_{y}$ at the desired strain (0.35\% EUL, $0.5 \%$ EUL, $0.1 \%$ offset, or $0.2 \%$ offset), and the constant $n$ is selected so that the shape of the curve generated by Eq. (2) serves as a reasonable lower-bound to the actual stress-strain curves. The parameters describing the RH curves used in this study are presented in Table A.1 in Appendix $\mathrm{A}^{3}$. The black dots indicate the intersection of the stress-strain curves with the value of $f_{y}$ at the strain used to for the different measurement methods. In Fig. 4, the three dots (left to right) represent $0.1 \%$ OM, 0.2\% OM, and 0.5\% EUL. The CODE and EPSH stress-strain curves used for the study are shown in Fig. 5 and the RH 29 curves are shown in Fig. 6. The RH 22 and RH 21 curves are similar in appearance to those shown in Fig. 6, though with a reduced initial slope.

\section{Concrete Stress-Strain Relationships}

Several stress-strain relationships to represent actual nonlinear stress-strain behavior of concrete in compression (Hognestad 1951; Mander, Priestly, and Park 1988; ACI Committee 408 2003; Nilson, Darwin, and Dolan 2010) were evaluated using a sensitivity analysis to ensure that the concrete model selected was appropriate for the overall analysis. Full details of analysis are

\footnotetext{
${ }^{3}$ Appendix A is available in the online version of this paper from ACI.
} 
presented by Wiss, Janney, Elstner Associates (2013). The stress-strain curves described by Nilson et al. (2010) were selected and those used for the analysis are illustrated in Fig. 7. The digitized stress-strain relationships for the concrete are given in Table A.2 in Appendix A.

\section{“Code” Member Strength}

Beams. Following Chapter 22 of ACI 318-14, the nominal flexural strengths $M_{n}$ of the beams (Fig. 2a) are computed based on an equivalent rectangular stress block using Eq. (3).

$$
M_{n}=A_{s} f_{s}\left(d-\frac{\beta_{1} c}{2}\right)
$$

where $A_{s}=$ cross-sectional area of longitudinal tension reinforcement; $f_{s}=$ stress in longitudinal reinforcement; $d$ = distance from the extreme compression fiber in the concrete to centroid of longitudinal tension reinforcement; $\beta_{1}=0.85$ for $f_{c}^{\prime} \leq 4000 \mathrm{psi}$ (28 MPa), 0.65 for $f_{c}^{\prime} \geq 8000$ psi (56 MPa), varying linearly between 0.85 and 0.65 for $f_{c}^{\prime}$ between 4000 and 8000 psi (28 and $56 \mathrm{MPa}) ; f_{c}^{\prime}=$ compressive strength of concrete; and $c=$ distance from extreme compression fiber to the neutral axis. The stress in the reinforcement $f_{s}$ equals $\varepsilon_{s} E_{s}$ until the yield strength $f_{y}$ is reached and then $f_{s}=f_{y}$ thereafter. The depth of the neutral axis $c$ is computed by satisfying the conditions of equilibrium and strain compatibility, assuming that strain varies linearly through the depth of the section using Eq. (4).

$$
A_{s} f_{s}=0.85 f_{c}^{\prime} b \beta_{1} c
$$

where $b=$ width of the section. In accordance with ACI 318-14, the limiting compressive strain in the concrete is set to 0.003 .

Columns. The strength of the columns (Fig. 2b, c, and d) is calculated based on the same assumptions used to calculate the strength of the beams. The nominal flexural strength $M_{n}$ of 
columns at a given axial load is computed by establishing moment equilibrium about the centroid of the section using Eq. (5).

$$
M_{n}=\sum_{i=1}^{n_{s}}\left[A_{s_{i}} f_{s_{i}}\left(d_{i}-\frac{h}{2}\right)\right]+0.85 f_{c}^{\prime} b \beta_{1} c\left(\frac{h}{2}-\frac{\beta_{1} c}{2}\right)
$$

where $n_{s}=$ number of layers of longitudinal reinforcement; $A_{s i}=$ area of the $i^{\text {th }}$ layer of longitudinal reinforcement; $f_{s i}=$ stress in the $i^{\text {th }}$ layer of longitudinal reinforcement; $d_{i}=$ distance from extreme compression fiber to centroid of the $i^{\text {th }}$ layer of longitudinal reinforcement; and $h=$ overall depth of the section.

As is the case of the beams, the strength according to ACI 318-14 is calculated by assuming that the steel is linearly elastic until the yield strength is reached and plastic thereafter. In the calculation, according to Code provisions, the extreme fiber strain in compression is 0.003 for the concrete, and different values of neutral axis depth $c$ are computed so that for a given nominal axial strength $P_{n}$ Eq. (6) is satisfied.

$$
\sum_{i=1}^{n_{s}}\left[A_{s_{i}} f_{s_{i}}\right]+P_{n}=0.85 f_{c}^{\prime} b \beta_{1} c
$$

For tied columns, the maximum axial load $P_{n \text {,max }}$ permitted by the Code is given by Eq. (7):

$$
P_{n, \max }=0.80\left[0.85 f_{c}^{\prime}\left(A_{g}-A_{s t}\right)+A_{s t} f_{y}\right]
$$

where $A_{s t}=$ total cross-sectional area of longitudinal reinforcement; $A_{s t}=\sum_{i=1}^{n_{s}}\left[A_{s_{i}} f_{s_{i}}\right]$; and $A_{g}$ $=$ gross cross-sectional area of the section $=b h$. 
Under Code criteria, the design flexural and, in the case of columns, design axial strengths are computed by multiplying the nominal strengths by the appropriate strengthreduction factor $\phi$, which ranges between 0.90 and 0.65 as a function of the net tensile strain in the extreme tensile layer of reinforcing steel at the calculated nominal strength (ACI Committee 318 2014).

\section{Analytical “Actual” Strength}

The analytical "actual" strength of a section is computed by assuming that plane sections remain plane and that the forces acting on the section are in equilibrium. Each reinforcing bar is treated as a discrete element, with its strain based on its location within the cross-section. For calculation of the force contributed by a reinforcing bar, it is assumed the bar follows one of the nonlinear stress-strain relationships shown in Table 1. The compression force contributed by the concrete is determined by integration of the stress profile calculated based on the strains in the concrete using the stress-strain relationships shown in Fig. 7. For these "actual" sectional strength computations, compressive strains in the concrete are permitted to exceed 0.003 because the relationships shown in Fig. 7 include realistic softening of the concrete, that is, decreasing strength with increasing strain for strains that exceed the strain corresponding to the maximum stress the concrete stress-strain relationship.

\section{COMPARISONS}

\section{Benchmark Strengths}

The strengths computed for the beams and columns shown Fig. 2 using the reinforcement stress-strain relationships shown in Table 1 are compared with three strengths that are treated as benchmarks: 
1. Nominal strength of the cross section ( $M_{n}$ or $M_{n}$ and $P_{n}$ ) computed according to Codepermitted assumptions (using the CODE stress-strain relationship).

2. Analytical strength of the cross-section computed assuming the EPSH stress-strain relationship for the reinforcing steel. This analytical strength is used as a benchmark because the EPSH stress-strain behavior is consistent with that assumed in the Code with the addition of realistic strain hardening.

3. Design strength of the cross-section ( $\phi M_{n}$ or $\phi M_{n}$ and $\phi P_{n}$ ) computed according to Codepermitted assumptions.

Because the stress in the EPSH relationship equals or exceeds the stress in the CODE relationship for the same strain, any comparisons between the strength of "EPSH members" and "CODE members" in which the EPSH relationship provides the lower strength are due to differences related to the concrete stress representation. A realistic concrete stress-strain relationship was used for EPSH members and the equivalent rectangular stress block was used for CODE members.

\section{Roundhouse Curves}

The analytical strengths computed for the cross sections using one of the gradually yielding (roundhouse) stress-strain relationships, $\mathrm{RH} 29, \mathrm{RH} 22$, or $\mathrm{RH} 21$, represent the best estimate of the strength of a member with reinforcement that has a gradually-yielding stressstrain relationship. Comparing an $\mathrm{RH}$ analytical strength with the benchmark strengths demonstrates:

1. Whether the analytical prediction is stronger or weaker than the code-calculated nominal strength. 
2. Whether the nominal strength of a section with RH steel is greater than or less than the same member with EPSH steel.

3. The relative value of the analytical strength to the Code-calculated design strength, providing an assessment of the "margin of safety" provided by the section with the realistic stress-strain relationship.

\section{Beams}

The reinforcement ratios for beams $\rho$ range from 0 to $6 \%$. In this discussion, however, consideration is limited to beams with reinforcement ratios between $\rho_{\min }$ and $0.75 \rho_{b}$, where $\rho_{\min }$ is the minimum reinforcement required by ACI 318 for flexural sections [nominally $0.4 \%$ and $0.3 \%$ for Grades 60 and 80 (420 and 550) reinforcement, respectively], and $\rho_{b}$ is the balanced reinforcement ratio for a singly-reinforced beam. The narrower range of reinforcement ratios is selected because, in practice, beams with reinforcement ratios greater than $0.75 \rho_{b}$ are economically inefficient and often impractical, and as a result, are seldom specified. An example of the comparisons for beams is illustrated in Fig. 8, which represents a beam with material strengths of $f_{c}^{\prime}=8,000(55.2 \mathrm{MPa})$ and $f_{y}=60,000 \mathrm{psi}$ (420 MPa). Using this figure, the Code-calculated nominal and design sectional strengths are shown for the full range of reinforcement ratios $\rho$ evaluated, along with the analytical strengths of interest (EPSH and various RH stress-strain curves). The ratio of the analytical strength to the Code nominal strength gives the relative strength ratio. Relative strength ratios greater than 1.0 represent analytical sectional strengths that are greater than the Code-calculated nominal strengths, and ratios less than 1.0 represent analytical sectional strengths that are weaker. If a nominal strength is significantly less than 1.0, a comparison between the analytical strength and the Code design 
strength (includes the $\phi$-factor) can be used to assess the margin of safety provided by the section.

Results. The results for the beams are summarized in Table 2. For $\rho_{\min }<\rho \leq 0.75 \rho_{b}$, all normalized reinforcement stress-strain relationships, whether for straight bars (EPHS and RH 29) or coiled bars (RH 22 and $\mathrm{RH} 21$ ), produce analytical strengths that equal or exceed the corresponding Code-calculated nominal strength. Further examination of the results (WJE 2013) reveals that, relative to the analytical results provided by the EPSH relationship, the other normalized stress-strain relationships produce analytical strengths that are at least equal to and often exceed the corresponding EPSH analytical strength.

\section{Columns}

For columns, the relative strengths are assessed at three locations on the axial loadbending moment $(P-M)$ interaction curves, as shown in Fig. 9, which represents a square column with reinforcement evenly distributed around the perimeter with material strengths $f_{c}^{\prime}=8,000$ (55 MPa) and $f_{y}=60,000 \mathrm{psi}(420 \mathrm{MPa}$ ), and a total reinforcement ratio based on the gross column cross-sectional area $\rho_{g}=4 \%$.

1. A quantitative assessment for a constant effective eccentricity, $e=M / P$, includes the point of maximum moment $M_{n}$ on the nominal Code-calculated $P_{n}-M_{n}$ interaction curve. This load case is selected because it is in this region of the $P-M$ curve where strengths are most noticeably different for the various reinforcement stress-strain relationships. The point on the Code-based nominal strength $P_{n}-M_{n}$ curve is used to define the eccentricity for comparisons with the analytical strength results corresponding to the EPSH, RH 290.1\% Offset, RH 29-0.2\% Offset, and RH 29-0.5\% EUL stress-strain curves. The line passing through the point of maximum nominal moment on the Code-calculated curve 
and the origin $(P=0, M=0)$ provides the constant effective eccentricity $e$ for use in the comparison. The same eccentricity $e$ is used to find the intersection with the analytical $P_{n}-M_{n}$ curves. The relative strength ratio is set equal to the ratio of analytical strength to Code-calculated strength (comparison can be made based on either $P_{n}$ or $M_{n}$ ).

2. A qualitative assessment where the moment $M_{n}$ is greatest for $P=P_{n \text {,max }}$ (maximum nominal axial strength permitted by ACI 318). A qualitative, rather than quantitative, evaluation is made for this loading condition because the strength results are little affected by the choice of reinforcement stress-strain relationship.

3. An assessment based on $M_{n}$ for $P=0$ (zero applied axial load) also demonstrates that, as observed for beams, the strength of columns under pure bending is little affected by the choice of reinforcement stress-strain relationship used to calculate sectional strength.

As for beams, in cases where the strength ratio is significantly less than 1.0, a comparison between the analytical strength and the Code design strength allows the margin of safety to be assessed.

Results. Reinforcement ratios $\rho_{g}=1$ and $2 \%$ are representative of most columns in practice. Columns with $\rho_{g}=3$ to $8 \%$ are less common and are generally less economical, with $8 \%$ being the maximum value of $\rho_{g}$ permitted by the ACI Code. Because the key goal of this study was to determine the feasibility of adopting the $0.2 \%$ offset method for defining yield strength in reinforcing steel, the discussion that follows emphasizes comparisons with analytical results for the RH steel stress-strain curves representing this method for defining yield strength (RH 29-0.2\%). Coiled reinforcement is not considered for columns because the common maximum size of coiled bars is No. 6 (19). 
Tables 3, A.3, and A.4 summarize the relative strengths at the eccentricity $e=M / P$ (see Fig. 9) that include the point of maximum nominal bending capacity $M_{n}$ on the interaction curve calculated in accordance with ACI 318-14 (CODE) for square columns with $\lambda=0.8$, rectangular columns with $\lambda=0.8$, and rectangular columns with $\lambda=0.6$. Because the square columns provide the lowest relative strength ratios, those results are shown in this paper (Table 3). The results for the rectangular columns are presented in Tables A.3 and A.4 in Appendix A. The rectangular columns with $\lambda=0.6$ provide the highest ratios (Table A.4).

For the columns with $f_{c}^{\prime}=5,000$ and 8,000 psi (34 and $55 \mathrm{MPa}$ ) and $\rho_{g}=1$ or $2 \%$, the RH 29-0.2\% and EPSH stress-strain relationships produce analytical strengths that are at least $99 \%$ and $102 \%$, respectively, of the corresponding Code-calculated nominal strength. The relative strength ratios for RH 29-0.2\% drop progressively with increasing $\rho_{g}$, reaching values at $\rho_{g}=8 \%$ of $0.93,0.95,0.93$ and 0.96 , respectively, for $f_{y}=60,000$ psi (420 MPa) with $f_{c}^{\prime}=5,000$ and 8,000 psi (34 and $55 \mathrm{MPa}$ ) and $f_{y}=80,000 \mathrm{psi}$ (550 MPa) with $f_{c}^{\prime}=5,000$ and 8,000 psi (34 and $552 \mathrm{MPa}$ ). The relative strength ratios for the columns with $f_{c}^{\prime}=12,000 \mathrm{psi}$ (83 MPa) and $\rho_{g}=1$ or $2 \%$ equal are at least 0.97 for all of the non-CODE stress-strain relationships. The lowest relative strength ratio for any of the combinations used in the analysis is $93 \%$, always for columns with $\rho_{g}=6$ or $8 \%$. An examination of the $P_{n}-M_{n}$ interaction curves reveals that the lower relative strengths occur only for combinations of moment and axial load where the strength-reduction factor $\phi$ is compression-controlled, resulting in $\phi=0.65$ for tied columns and 0.75 for spiral columns, a result considered by ACI Committee 318 as providing an adequate margin of safety. For $f_{c}^{\prime}=12,000$ psi (82.7 MPa), with one exception, the EPSH stress-strain relationships (combined with realistic concrete stress-strain curve) produce relative strength 
ratios of 0.97 to 0.99 , suggesting that the Code-permitted equivalent stress block may provide a slightly unconservative representation of column strength when used to represent higher-strength concretes. This observation has been noted by others (Ibrahim and MacGregor 1997).

Comparisons of column strengths with those provided by the EPSH relationship (also summarized in Tables 3, A.3, and A.4) show that the RH-0.2\% stress-strain relationships provide strengths that range from 92 to $100 \%$ of the strength provided by the EPSH relationship. The “worst case” ratio, 92\%, corresponds to a single instance that involves a square column with $\rho_{g}=$ 8\%, $f_{c}^{\prime}=5,000$ psi (34 MPa), and $f_{y}=60,000$ psi (420 MPa). For columns with $\rho_{g}=1$ or $2 \%$, analytical strengths for RH $29-0.2 \%$ equal or exceed $95 \%$ of that provided by the EPSH stressstrain relationship. Again, these lower relative strengths occur under combinations of moment and axial load where the strength-reduction factor $\phi=0.65$ for tied columns and 0.75 for spiral columns. This again suggests that that the Code-permitted equivalent stress block may provide an unconservative representation of column strength when used to represent higher-strength concretes.

An analysis of the interaction curves where the bending moment $M_{n}$ is a maximum for $P$ $=P_{n, \max }$ is illustrated in Fig. 9. When comparing the strengths provided by the various stressstrain relationships for reinforcement, whether EPSH or RH, little difference is observed for columns with reinforcement ratios $\rho_{g}$ of 1 and $2 \%$. Regardless of the stress-strain relationship, columns with concrete strengths $f_{c}^{\prime}=5,000$ and 8,000 psi (34.4 and 55.2 MPa) and longitudinal reinforcement ratios $\rho_{g} \leq 4 \%$ produce strengths in excess of the Code-calculated nominal strength (WJE 2013). For columns with $f_{c}^{\prime}=12,000$ psi (83 MPa), the analytical strengths, including those based on the EPSH relationship, are below the Code-calculated strengths, with a minimum value of 95\% (WJE 2013). 
For columns with applied axial load $P=0$ (Fig. 9), examination of the interaction curves indicates that the EPSH stress-strain relationship consistently provides analytical strengths that are essentially identical to the Code-calculated nominal strengths (WJE 2013). With a few exceptions, the RH stress-strain relationships provide sectional strengths that equal or exceed the Code-calculated and EPSH relationships. The exceptions occur only for concrete strength $f_{c}^{\prime}=$ $5,000 \mathrm{psi}(34 \mathrm{MPa})$ at the relatively high reinforcement ratios $\rho_{g}=6$ and $8 \%$, which produce minimum relative strengths of about $95 \%$.

\section{DISCUSSION}

As demonstrated by the comparisons for beams with different reinforcement stress-strain curves and methods of defining yield strength, it is clear that beams with practical quantities of longitudinal reinforcement have analytical strengths that are always in excess of the Codecalculated nominal strength, including those reinforced with RH reinforcement normalized to the $0.2 \%$ offset yield strength.

An examination of the results for columns with concrete strengths $f_{c}^{\prime}=5,000$ and 8,000 psi (34 and $55 \mathrm{MPa}$ ) indicates that the majority of the sections with gradually yielding (RH) reinforcement normalized to the $0.2 \%$ offset yield strength have analytical strengths that are at least $99 \%$ of the corresponding Code-calculated nominal strength. For columns with any of the three concrete strengths with longitudinal reinforcement at or near the Code-permitted maximum ratio $\rho=8 \%$, that is, columns that are often considered to be impractical (and rarely used), strength ratios as low as $93 \%$ are obtained when the $0.2 \%$ offset method is used to define yield strength. This case, however, is less concerning because the region of the interaction diagram where this occurs coincides with the region in which $\phi=0.65$ for tied columns and 0.75 for spiral columns. 
Considering the comparisons and also observing that (1) less than $2 \%$ of all stress-strain curves for straight reinforcing bars exhibit gradual yielding and (2) coiled reinforcement is not used for columns because the common maximum size of coiled bars is No. 6 (19 mm), the probability is extremely low that the analytical sectional strength loss will be as high as $7 \%$ under a load regime for which the Code-specified $\phi$-factor is 0.65 or 0.75 . Considering further that the average yield strength of reinforcement ranges from 1.06 to 1.20 times the specified yield strength (Bournonville, Dahnke, and Darwin 2004), reinforced concrete columns will continue to possess an ample margin of safety.

Based on these observations, a proposal to measure yield strength using the $0.2 \%$ offset

method was submitted for consideration by ACI Committee 318 and subsequently approved by the committee for adoption in ACI 318-14.

\section{SUMMARY AND CONCLUSIONS}

Analytical strengths of reinforced concrete beams and columns incorporating reinforcing steel stress-strain curves with and without a sharp yield plateau and realistic representations of the nonlinear stress-strain behavior of concrete were compared with strengths obtained using an idealized elastic-plastic stress-strain curve and equivalent concrete stress block, as permitted by the ACI Building Code. The steel stress-strain curves used to calculate the analytical strengths included an elastic-plastic-strain-hardening curve and gradually yielding curves with yield strengths defined based on offset values of 0.1 and $0.2 \%$ and extension under load of 0.35 and 0.5\%. Comparisons were emphasized where yield strengths were defined based on an offset of $0.2 \%$. The analyses included steel yield strengths of 60,000 and 80,000 psi (420 and $550 \mathrm{MPa}$ ) and concrete compressive strengths of 5,000 and 8,000 psi (34 and $55 \mathrm{MPa}$ ) for beams and 5,000, 8,000, and 12,000 psi (34, 55, and $83 \mathrm{MPa})$ for columns. Flexural reinforcement ratios 
ranged from 0 to $6 \%$ per beams, and total reinforcement ratios ranged from 1 to $8 \%$ for columns. The goal of the comparisons was to determine the feasibility of using the $0.2 \%$ offset method in place of the $0.35 \%$ and $0.5 \%$ elongation-under-load methods to define the yield strength of concrete steel reinforcement.

The comparisons demonstrate that:

1. For the practical range of reinforcement ratios in beams (below three-quarters of the balanced ratio), realistic stress-strain curves representing both sharply yielding and gradually yielding reinforcement produce analytical strengths that equal or exceed the corresponding Code-calculated nominal strengths.

2. For columns, the greatest sensitivity of column strength to steel stress-strain curve shape occurs at the point of maximum nominal bending capacity. At this combination of bending moment and axial load, columns with compressive strengths of 5,000 and 8,000 psi (34 and $55 \mathrm{MPa}$ ) and total reinforcement ratios of 1 or $2 \%$ exhibit little impact of the stress-strain relationship selected. At the same reinforcement ratios combined with a concrete compressive strength of 12,000 psi (83 MPa), the analytical strengths are at least $97 \%$ of the Code-calculated strength. The relative strengths drop as the reinforcement ratio increases. The lowest ratio of analytical to Code-calculated strength for columns containing reinforcement with yield strength defined based the $0.2 \%$ offset method, $93 \%$, occurs at total reinforcement ratios of 6 to $8 \%$; in all cases the lower relative strengths occur under combinations of moment and axial load where the strength-reduction factor is 0.65 for tied columns and 0.75 for spirally reinforced columns, thus maintaining an adequate margin of safety. 
3. Use of the $0.2 \%$ offset method to define the yield strength of gradually yielding reinforcing steel is safe and realistic.

\section{AUTHORS BIOS}

Conrad Paulson, FACI, is a Principal in the Los Angeles (Pasadena), California office of Wiss, Janney, Elstner Associates, Inc., where his practice focuses on structural and seismic engineering for existing structures of all types. He is a member of ACI Subcommittees 318-B, Anchorage and Reinforcement, and 318-R, High-Strength Reinforcement, and past chair of Committees 215, Fatigue of Concrete, and 439, Steel Reinforcement.

ACI Member Jeffrey M. Rautenberg is an Associate III in the San Francisco (Emeryville), California office of Wiss, Janney, Elstner Associates, Inc. He studied at Purdue University between 2004 and 2011 where he earned his BSCE, MSCE, and PhD in structural engineering. He is a member of ACI Committee 374, Performance-Based Seismic Design of Concrete Buildings and an associate member of ACI Committee 445, Shear and Torsion.

ACI Member Scott K. Graham is a Senior Associate in the Chicago, Illinois office of Wiss, Janney, Elstner Associates, Inc. His main areas of interest include load testing of many structural components or systems both in the laboratory and in the field. He is a member of ACI Committees 408, Bond and Development of Steel Reinforcement; 408-A Mechanical Reinforcing Bar Anchorages and Splices, 439, Steel Reinforcement and a member of the CRSI Reinforcement Anchorages and Splices Committee.

David Darwin, FACI, is the Deane E. Ackers Distinguished Professor and Chair of the Department of Civil, Environmental, and Architectural Engineering at the University of Kansas and a Past President of ACI. He is a member of ACI Committees 222, Corrosion of Metals in Concrete; 224, Cracking; Subcommittee 318-B, Anchorage and Reinforcement; and Joint ACI- 
ASCE Committees 408, Bond and Development of Steel Reinforcement; 445, Shear and Torsion; and 446, Fracture Mechanics of Concrete.

\section{ACKNOWLEDGEMENTS}

This research was funded by the Charles Pankow Foundation. Gary Klein of Wiss, Janney, Elstner Associates served as project advisor. The Concrete Reinforcing Steel Institute (CRSI) coordinated the collection of industry-recorded stress-strain curves and granted access to a data base of mill certificate tensile properties.

\section{REFERENCES}

ACI Committee 318, 1956, Building Code Requirements for Reinforced Concrete (ACI 318-56), American Concrete Institute, Detroit, MI, 74 pp.

ACI Committee 318, 1971, Building Code Requirements for Reinforced Concrete (ACI 318-71), American Concrete Institute, Detroit, MI, 78 pp.

ACI Committee 318, 2014, Building Code Requirements for Structural Concrete (ACI 318-14) and Commentary (ACI 318R-14), American Concrete Institute, Farmington Hills, MI, 519 pp.

ACI Committee 408, 2003, Bond and Development of Straight Reinforcing Bars in Tension (ACI 408R-03), American Concrete Institute, Farmington Hills, MI, 49 pp.

ASTM A15-35, 1935, Specification for Billet-Steel Bars for Concrete Reinforcement, Amer. Soc. for Testing and Materials, Philadelphia, PA.

ASTM 615-76a, 1976, Standard Specification for Deformed and Plain Billet-Steel Bars for Concrete Reinforcement, ASTM International, Philadelphia, PA, 6 pp.

ASTM A615/A615M-09, 2009, Standard Specification for Deformed and Plain Carbon-Steel Bars for Concrete Reinforcement, ASTM International, West Conshohocken, PA, 6 pp.

ASTM A615/A615M-09b, 2009, Standard Specification for Deformed and Plain Carbon-Steel Bars for Concrete Reinforcement, ASTM International, West Conshohocken, PA, 6 pp.

ASTM A615/A615M-14, 2014, Standard Specification for Deformed and Plain Carbon-Steel Bars for Concrete Reinforcement, ASTM International, West Conshohocken, PA, 5 pp.

ASTM A706/A706M-09, 2009, Standard Specification for Low-Alloy Steel Deformed and Plain Bars for Concrete Reinforcement, ASTM International, West Conshohocken, PA, 6 pp. 
ASTM A706/A706M-09b, 2009, Standard Specification for Low-Alloy Steel Deformed and Plain Bars for Concrete Reinforcement, ASTM International, West Conshohocken, PA, 6 pp.

ASTM A706/A706M-14, 2014, Standard Specification for Low-Alloy Steel Deformed and Plain Bars for Concrete Reinforcement, ASTM International, West Conshohocken, PA, 7 pp.

ASTM A955/A955M-14, 2014, Deformed and Plain Stainless-Steel Bars for Concrete Reinforcement, ASTM International, West Conshohocken, PA, 13 pp.

ASTM A996/A996M-14a, 2014, Standard Specification for Rail-Steel and Axle-Steel Deformed Bars for Concrete Reinforcement, ASTM International, West Conshohocken, PA, 5 pp.

ASTM A1035/A1035M-14, 2014, Standard Specification for Deformed and Plain, Low-Carbon, Chromium, Steel Bars for Concrete Reinforcement, ASTM International, West Conshohocken, PA, 7 pp.

Bournonville, M.; Dahnke, J.; and Darwin, D., 2004, "Statistical Analysis of the Mechanical Properties and Weight of Reinforcing Bars," SL Report 04-1, University of Kansas Center for Research, Lawrence, KS, Dec., 194 pp.

Hognestad, E., 1951, "A Study of Combined Bending and Axial Load in Reinforced Concrete Members,” Bulletin Series No. 399, Univ. of Illinois Engrg. Experiment Station, Urbana, Ill.

Ibrahim, H. H. H., and J. G. MacGregor, 1997, "Modification of the ACI Rectangular Stress Block for High-Strength Concrete,” ACI Struct. J., Jan.-Feb., pp. 40-48.

Mander, J. B.; M. J. N. Priestley; and R. Park, 1988, “Theoretical Stress-Strain Model for Confined Concrete” J. Struct. Engrg., ASCE, V. 114, No. 8, August, pp. 1804-1826.

Nilson, A. H.; Darwin, D.; and Dolan, C. W., 2010, Design of Concrete Structures, 14th ed., McGraw-Hill, 795 pp.

Ramberg, W., and Osgood, R., 1943, "Description of Stress-Strain Curves by Three Parameters," Technical Note No.902, National Advisory Committee for Aeronautics, National Bureau of Standards, Washington, D.C., April 8, 28 pp.

Whitney, C. S., 1937, "Design of Reinforced Concrete Members under Flexure or Combined Flexure and Direct Compression,” J. ACI, Proceedings V. 33, No. 3, Mar.-Apr., pp. 483-498.

Wiss, Janney, Elstner and Associates, Inc. (WJE), 2013, "Determination of Yield Strength for Nonprestressed Steel Reinforcement,” WJE No. 2013.4171, Dec., 103 pp. 


\section{List of Tables:}

Table 1-Normalized stress-strain relationships for reinforcement

Table 2-Summary of results for parametric study of beams

Table 3-Summary of results for square columns $(\gamma=\mathbf{0 . 8})$

Table A.1-Parameters describing roundhouse (RH) curves $^{4}$

Table A.2-Digitized stress-strain relationships for concrete

Table A.3-Summary of results for rectangular column sections $(\gamma=\mathbf{0 . 8})$

Table A.4-Summary of results for rectangular column sections $(\gamma=0.6)$

\section{List of Figures:}

Fig. 1-Stress-strain diagrams showing methods of yield strength determination.

Fig. 2-Cross sections of members used in analyses.(a) Beam, (b) square column with $\gamma=0.8$, (c)rectangular column with $\gamma=0.8$, and (d) rectangular column with $\gamma=0.60$.

Fig. 3-Representative actual reinforcing steel stress-strain curves, illustrating various elationship characterization categories.

Fig. 4-Example of representative actual stress-strain curves (lighter-weight lines) and resulting normalized stress-strain relationships (heavy-weight lines) [Grade 60 (420) coiled bar reinforcement]. Note: $1 \mathrm{ksi}=6.895 \mathrm{MPa}$.

Fig. 5-Normalized CODE specified (solid lines) and EPSH (dashed lines) stress-strain relationships (Grades 60 and 80 (420 and 550). Note: $1 \mathrm{ksi}=6.895 \mathrm{MPa}$.

Fig. 6-Normalized stress-strain relationships for RH 29 curves (Grade 60 (420) 0.1\% and 0.2\% offset and 0.5\% EUL and Grade 80 (550) 0.1\% and 0.2\% offset and 0.35\% EUL]. Note: $1 \mathrm{ksi}=$ $6.895 \mathrm{MPa}$.

Fig. 7-Concrete stress-strain curves used for analyses for $\mathrm{f}_{\mathrm{c}}^{\prime}=5,000,8,000$, and 12,000 psi.

Note: $1000 \mathrm{psi}=1 \mathrm{ksi}=6.895 \mathrm{MPa}$.

Fig. 8-Representative flexural strength vs. reinforcement ratios (beams with $\mathrm{f}_{\mathrm{c}}^{\prime}=8,000$ psi and $\mathrm{f}_{\mathrm{y}}=60,000$ psi). Note: $1000 \mathrm{psi}=6.895 \mathrm{MPa}$.

Fig. 9- Representative column axial load-bending moment interaction diagram (square column with $\mathrm{f}_{\mathrm{c}}^{\prime}=8,000 \mathrm{psi}, \mathrm{f}_{\mathrm{y}}=60,000 \mathrm{psi}$, and $\rho_{\mathrm{g}}=4$ percent) illustrating where relative strengths are evaluated. Note: 1000 psi $=6.895 \mathrm{MPa}$.

\footnotetext{
${ }^{4}$ Appendix A is available in the online version of this paper from ACI.
} 
Table 1 -Normalized stress-strain relationships for reinforcement

\begin{tabular}{|c|c|c|c|c|c|}
\hline \multirow{2}{*}{$\begin{array}{l}\text { Yield Strength of } \\
\text { Reinforcement, } f_{y} \text {, } \\
\text { psi }\end{array}$} & \multicolumn{5}{|c|}{ Yield Measurement Method } \\
\hline & $\begin{array}{l}\text { Observed } \\
\text { Yield Point }\end{array}$ & $\begin{array}{c}\text { Offset Method at } \\
0.1 \% \text { Offset }\end{array}$ & $\begin{array}{c}\text { Offset Method at } \\
0.2 \% \text { Offset }\end{array}$ & $\begin{array}{c}\text { 0.35\% Extension } \\
\text { Under Load (EUL) }\end{array}$ & $\begin{array}{c}\text { 0.5\% Extension } \\
\text { Under Load (EUL) }\end{array}$ \\
\hline 80,000 & $\begin{array}{l}\text { CODE } \\
\text { EPSH }\end{array}$ & $\begin{array}{l}\text { RH } 29 \\
\text { RH } 21\end{array}$ & $\begin{array}{l}\text { RH } 29 \\
\text { RH } 21\end{array}$ & RH 29 & N/A \\
\hline 60,000 & $\begin{array}{l}\text { CODE } \\
\text { EPSH }\end{array}$ & $\begin{array}{l}\text { RH } 29 \\
\text { RH } 22\end{array}$ & $\begin{array}{l}\text { RH } 29 \\
\text { RH } 22\end{array}$ & N/A & $\begin{array}{l}\text { RH } 29 \\
\text { RH } 22\end{array}$ \\
\hline
\end{tabular}

Note: $1000 \mathrm{psi}=6.895 \mathrm{MPa}$

Table 2-Summary of results for parametric study of beams

\begin{tabular}{|c|c|c|c|c|}
\hline$f y$, psi & $f_{c}^{\prime}$, psi & $\begin{array}{c}\text { Reinforcement Ratio } \\
\text { Range of Interest* }\end{array}$ & $\begin{array}{c}\text { Reinforcement Stress- } \\
\text { Strain Relationship }\end{array}$ & $\begin{array}{c}\text { Range of Strength Ratio } \\
\text { Relative to CODE** }\end{array}$ \\
\hline \multirow{2}{*}{60,000} & 5,000 & $0.4 \%<\rho<2.5 \%$ & $\begin{array}{c}\text { EPSH } \\
\text { RH 29-0.1\% Offset } \\
\text { RH 29-0.2\% Offset } \\
\text { RH 29-0.5\% EUL } \\
\text { RH 22-0.1\% Offset } \\
\text { RH 22-0.2\% Offset } \\
\text { RH 22-0.5\% EUL } \\
\text { CODE } \\
\end{array}$ & $\begin{array}{l}1.0-1.2 \\
1.1-1.4 \\
1.0-1.3 \\
1.0-1.2 \\
1.0-1.4 \\
1.0-1.3 \\
1.0-1.3 \\
1.0-1.0\end{array}$ \\
\hline & 8,000 & $0.4 \%<\rho<3.5 \%$ & $\begin{array}{c}\text { EPSH } \\
\text { RH 29-0.1\% Offset } \\
\text { RH 29-0.2\% Offset } \\
\text { RH 29-0.5\% EUL } \\
\text { RH 22-0.1\% Offset } \\
\text { RH 22-0.2\% Offset } \\
\text { RH 22-0.5\% EUL } \\
\text { CODE } \\
\end{array}$ & $\begin{array}{l}1.0-1.3 \\
1.1-1.4 \\
1.0-1.4 \\
1.0-1.3 \\
1.1-1.4 \\
1.0-1.3 \\
1.0-1.3 \\
1.0-1.0\end{array}$ \\
\hline \multirow{2}{*}{80,000} & 5,000 & $0.3 \%<\rho<1.7 \%$ & $\begin{array}{c}\text { EPSH } \\
\text { RH 29-0.35\% EUL } \\
\text { RH 29-0.1\% Offset } \\
\text { RH 29-0.2\% Offset } \\
\text { RH 21-0.1\% Offset } \\
\text { RH 21-0.2\% Offset } \\
\text { CODE } \\
\end{array}$ & $\begin{array}{l}1.0-1.1 \\
1.1-1.4 \\
1.1-1.3 \\
1.0-1.3 \\
1.1-1.4 \\
1.0-1.3 \\
1.0-1.0\end{array}$ \\
\hline & 8,000 & $0.3 \%<\rho<2.3 \%$ & $\begin{array}{c}\text { EPSH } \\
\text { RH 29-0.35\% EUL } \\
\text { RH 29-0.1\% Offset } \\
\text { RH 29-0.2\% Offset } \\
\text { RH 21-0.1\% Offset } \\
\text { RH 21-0.2\% Offset } \\
\text { CODE }\end{array}$ & $\begin{array}{l}1.0-1.2 \\
1.1-1.4 \\
1.1-1.4 \\
1.0-1.3 \\
1.0-1.5 \\
1.0-1.4 \\
1.0-1.0\end{array}$ \\
\hline
\end{tabular}

*Range approximately from $\rho_{\text {min }}$ to $0.75 \rho_{b}$

$* *$ Ratio of analytically-predicted sectional strength to Code-calculated nominal strength

Note: $1000 \mathrm{psi}=6.895 \mathrm{MPa}$ 
Table 3-Summary of results for square columns $(\gamma=\mathbf{0 . 8})$

\begin{tabular}{|c|c|c|c|c|c|c|c|c|c|c|c|c|c|c|}
\hline \multirow{3}{*}{$f_{y}, \mathrm{psi}$} & \multirow{3}{*}{, psi } & \multirow{3}{*}{$\begin{array}{l}\text { Reinforcement } \\
\text { Stress-Strain } \\
\text { Relationship }\end{array}$} & \multicolumn{6}{|c|}{ Longitudinal Reinforcement Ratio, $\rho_{g}$} & \multicolumn{6}{|c|}{ Longitudinal Reinforcement Ratio, $\rho_{g}$} \\
\hline & & & $1 \%$ & $2 \%$ & $3 \%$ & $4 \%$ & $6 \%$ & $\mathbf{8 \%}$ & $1 \%$ & $2 \%$ & $3 \%$ & $4 \%$ & $6 \%$ & $8 \%$ \\
\hline & & & \multicolumn{6}{|c|}{ Strength Ratio Relative to CODE } & \multicolumn{6}{|c|}{ Strength Ratio Relative to EPSH } \\
\hline \multirow{15}{*}{60,000} & \multirow{5}{*}{5,000} & EPSH & 1.04 & 1.03 & 1.03 & 1.02 & 1.01 & 1.01 & 1.00 & 1.00 & 1.00 & 1.00 & 1.00 & 1.00 \\
\hline & & RH 29-0.1\% Offset & 1.03 & 1.00 & 0.99 & 0.98 & 0.97 & 0.96 & 0.98 & 0.97 & 0.96 & 0.96 & 0.96 & 0.95 \\
\hline & & RH $29-0.2 \%$ Offset & 1.01 & 0.99 & 0.97 & 0.96 & 0.94 & 0.93 & 0.97 & 0.95 & 0.94 & 0.94 & 0.93 & 0.92 \\
\hline & & RH 29-0.5\% EUL & 1.01 & 0.98 & 0.96 & 0.94 & 0.93 & 0.91 & 0.97 & 0.95 & 0.93 & 0.92 & 0.92 & 0.90 \\
\hline & & CODE & 1.00 & 1.00 & 1.00 & 1.00 & 1.00 & 1.00 & 0.96 & 0.97 & 0.97 & 0.98 & 0.99 & 0.99 \\
\hline & \multirow{5}{*}{8,000} & EPSH & 1.07 & 1.08 & 1.06 & 1.05 & 1.04 & 1.04 & 1.00 & 1.00 & 1.00 & 1.00 & 1.00 & 1.00 \\
\hline & & RH $29-0.1 \%$ Offset & 1.07 & 1.05 & 1.03 & 1.02 & 1.00 & 1.00 & 1.00 & 0.97 & 0.97 & 0.97 & 0.96 & 0.97 \\
\hline & & RH $29-0.2 \%$ Offset & 1.06 & 1.03 & 1.01 & 0.99 & 0.98 & 0.97 & 0.99 & 0.96 & 0.96 & 0.94 & 0.94 & 0.94 \\
\hline & & RH 29-0.5\% EUL & 1.06 & 1.03 & 1.00 & 0.98 & 0.96 & 0.95 & 0.99 & 0.95 & 0.94 & 0.94 & 0.92 & 0.92 \\
\hline & & CODE & 1.00 & 1.00 & 1.00 & 1.00 & 1.00 & 1.00 & 0.93 & 0.93 & 0.95 & 0.95 & 0.96 & 0.97 \\
\hline & \multirow{5}{*}{12,000} & EPSH & 0.98 & 0.99 & 0.99 & 0.99 & 0.99 & 1.00 & 1.00 & 1.00 & 1.00 & 1.00 & 1.00 & 1.00 \\
\hline & & RH 29-0.1\% Offset & 0.97 & 0.98 & 0.97 & 0.96 & 0.95 & 0.95 & 0.99 & 0.99 & 0.97 & 0.97 & 0.96 & 0.96 \\
\hline & & RH $29-0.2 \%$ Offset & 0.97 & 0.98 & 0.96 & 0.94 & 0.93 & 0.93 & 0.99 & 0.99 & 0.96 & 0.95 & 0.94 & 0.93 \\
\hline & & RH 29-0.5\% EUL & 0.97 & 0.97 & 0.95 & 0.93 & 0.92 & 0.92 & 0.99 & 0.98 & 0.96 & 0.94 & 0.93 & 0.92 \\
\hline & & & 1.00 & 1.00 & 1.00 & 1.00 & 1.00 & 1.00 & 1.02 & 1.01 & 1.01 & 1.01 & 1.01 & 1.00 \\
\hline \multirow{15}{*}{80,000} & \multirow{5}{*}{5,000} & EPSH & 1.04 & 1.02 & 1.01 & 1.01 & 1.00 & 1.00 & 1.00 & 1.00 & 1.00 & 1.00 & 1.00 & 1.00 \\
\hline & & RH 29-0.35\% EUL & 1.02 & 0.99 & 0.99 & 0.98 & 0.96 & 0.96 & 0.98 & 0.98 & 0.98 & 0.97 & 0.96 & 0.96 \\
\hline & & RH 29-0.1\% Offset & 1.01 & 0.99 & 0.98 & 0.97 & 0.95 & 0.95 & 0.98 & 0.97 & 0.97 & 0.96 & 0.95 & 0.96 \\
\hline & & RH $29-0.2 \%$ Offset & 1.00 & 0.97 & 0.96 & 0.95 & 0.93 & 0.93 & 0.97 & 0.95 & 0.95 & 0.94 & 0.93 & 0.93 \\
\hline & & CODE & 1.00 & 1.00 & 1.00 & 1.00 & 1.00 & 1.00 & 0.97 & 0.98 & 0.99 & 0.99 & 1.00 & 1.00 \\
\hline & \multirow{5}{*}{8,000} & EPSH & 1.07 & 1.08 & 1.06 & 1.03 & 1.04 & 1.03 & 1.00 & 1.00 & 1.00 & 1.00 & 1.00 & 1.00 \\
\hline & & RH $29-0.35 \%$ EUL & 1.06 & 1.07 & 1.03 & 1.02 & 1.01 & 0.99 & 1.00 & 0.99 & 0.98 & 0.98 & 0.98 & 0.97 \\
\hline & & RH 29-0.1\% Offset & 1.06 & 1.06 & 1.03 & 1.01 & 1.00 & 0.98 & 1.00 & 0.98 & 0.97 & 0.97 & 0.97 & 0.96 \\
\hline & & RH $29-0.2 \%$ Offset & 1.06 & 1.05 & 1.01 & 0.99 & 0.98 & 0.96 & 0.99 & 0.97 & 0.95 & 0.95 & 0.95 & 0.93 \\
\hline & & CODE & 1.00 & 1.00 & 1.00 & 1.00 & 1.00 & 1.00 & 0.94 & 0.92 & 0.95 & 0.97 & 0.96 & 0.97 \\
\hline & \multirow{5}{*}{12,000} & EPSH & 0.98 & 0.98 & 0.99 & 0.99 & 0.99 & 0.99 & 1.00 & 1.00 & 1.00 & 1.00 & 1.00 & 1.00 \\
\hline & & RH 29-0.35\% EUL & 0.97 & 0.97 & 0.98 & 0.97 & 0.96 & 0.96 & 1.00 & 0.99 & 0.99 & 0.98 & 0.97 & 0.97 \\
\hline & & RH $29-0.1 \%$ Offset & 0.97 & 0.97 & 0.98 & 0.96 & 0.95 & 0.95 & 0.99 & 0.98 & 0.98 & 0.97 & 0.96 & 0.96 \\
\hline & & RH $29-0.2 \%$ Offset & 0.97 & 0.97 & 0.97 & 0.95 & 0.93 & 0.93 & 0.99 & 0.99 & 0.98 & 0.96 & 0.94 & 0.94 \\
\hline & & CODE & 1.00 & 1.00 & 1.00 & 1.00 & 1.00 & 1.00 & 1.02 & 1.02 & 1.01 & 1.01 & 1.01 & 1.01 \\
\hline
\end{tabular}

Note: 1000 psi $=6.895 \mathrm{MPa}$ 


\section{APPENDIX A}

Table A.1-Parameters describing roundhouse (RH) curves

\begin{tabular}{|c|c|c|c|c|}
\hline $\boldsymbol{f}_{\boldsymbol{y}}$, psi & Reinforcement Stress-Strain Relationship & $\boldsymbol{E}, \mathbf{k s i}$ & $\boldsymbol{\alpha}\left(\boldsymbol{f}_{\boldsymbol{y}} / \boldsymbol{E}\right)$ & $\boldsymbol{n}$ \\
\hline \multirow{5}{*}{60,000} & RH 29-0.1\% Offset & 29,000 & 0.00100 & 10 \\
\cline { 2 - 5 } & RH 29-0.2\% Offset & 29,000 & 0.00200 & 10 \\
\cline { 2 - 5 } & RH 29-0.5\% EUL & 29,000 & 0.00293 & 10 \\
\cline { 2 - 5 } & RH 22-0.1\% Offset & 22,000 & 0.00100 & 10 \\
\cline { 2 - 5 } & RH 22-0.2\% Offset & 22,000 & 0.00200 & 10 \\
\hline \multirow{3}{*}{80,000} & RH 22-0.5\% EUL & 22,000 & 0.00227 & 10 \\
\cline { 2 - 5 } & RH 29-0.35\% EUL & 29,000 & 0.00074 & 9 \\
\cline { 2 - 5 } & RH 29-0.1\% Offset & 29,000 & 0.00100 & 9 \\
\cline { 2 - 5 } & RH 29-0.2\% Offset & 29,000 & 0.00200 & 9 \\
\cline { 2 - 5 } & RH 21-0.1\% Offset & 21,000 & 0.00100 & 8 \\
\hline
\end{tabular}

Note: $1000 \mathrm{psi}=6.895 \mathrm{MPa}$

Table A.2-Digitized stress-strain relationships for concrete

\begin{tabular}{|c|c|c|c|c|c|}
\hline \multicolumn{7}{|c|}{ Concrete compressive strength, $\boldsymbol{f}_{c}^{\prime}$} \\
\hline \multicolumn{2}{|c|}{$\mathbf{5 , 0 0 0}$ psi } & \multicolumn{2}{c|}{$\mathbf{8 , 0 0 0}$ psi } & \multicolumn{2}{c|}{$\mathbf{1 2 , 0 0 0}$ psi } \\
\hline Stress, psi & Strain & Stress, psi & Strain & Stress, psi & 0.00000 \\
\hline 0 & 0.00000 & 0 & 0.00000 & 0 & 0.00025 \\
\hline 970 & 0.00025 & 1,300 & 0.00025 & 1,340 & 0.00050 \\
\hline 1,860 & 0.00050 & 2,500 & 0.00050 & 2,660 & 0.00075 \\
\hline 2,680 & 0.00075 & 3,600 & 0.00075 & 3,970 & 0.00100 \\
\hline 3,390 & 0.00100 & 4,620 & 0.00100 & 5,210 & 0.00125 \\
\hline 3,970 & 0.00125 & 5,530 & 0.00125 & 6,410 & 0.00150 \\
\hline 4,410 & 0.00150 & 6,340 & 0.00150 & 7,540 & 0.00175 \\
\hline 4,750 & 0.00175 & 7,000 & 0.00175 & 8,630 & 0.00200 \\
\hline 4,950 & 0.00200 & 7,520 & 0.00200 & 9,640 & 0.00225 \\
\hline 5,000 & 0.00225 & 7,860 & 0.00225 & 10,540 & 0.00250 \\
\hline 4,870 & 0.00250 & 8,000 & 0.00250 & 11,320 & 0.00275 \\
\hline 4,450 & 0.00275 & 7,800 & 0.00275 & 11,810 & 0.00294 \\
\hline 3,790 & 0.00300 & 6,870 & 0.00300 & 12,000 & 0.00300 \\
\hline 2,970 & 0.00325 & 5,410 & 0.00325 & 11,970 & 0.00325 \\
\hline 2,080 & 0.00351 & 0 & 0.00360 & 11,190 & 0.00338 \\
\hline 0 & 0.00440 & & & 8,970 & 0.00360 \\
\hline
\end{tabular}

Note: $1000 \mathrm{psi}=6.895 \mathrm{MPa}$ 
Table A.3-Summary of results for rectangular column sections $(\gamma=\mathbf{0 . 8})$

\begin{tabular}{|c|c|c|c|c|c|c|c|c|c|c|c|c|c|c|}
\hline \multirow{3}{*}{$f_{y}, \mathrm{psi}$} & \multirow{3}{*}{$\begin{array}{l}f_{c}^{\prime} \\
\text { psi }\end{array}$} & \multirow{3}{*}{$\begin{array}{c}\text { Reinforcement Stress-Strain } \\
\text { Relationship }\end{array}$} & \multicolumn{6}{|c|}{$\begin{array}{l}\text { Longitudinal Reinforcement Ratio, } \\
\qquad \rho_{g}\end{array}$} & \multicolumn{6}{|c|}{\begin{tabular}{|} 
Longitudinal Reinforcement Ratio, \\
$\rho_{g}$ \\
\end{tabular}} \\
\hline & & & $1 \%$ & $2 \%$ & $3 \%$ & $4 \%$ & $6 \%$ & $\mathbf{8 \%}$ & $1 \%$ & $2 \%$ & $3 \%$ & $4 \%$ & $6 \%$ & $8 \%$ \\
\hline & & & \multicolumn{6}{|c|}{ Strength Ratio Relative to CODE } & \multicolumn{6}{|c|}{ Strength Ratio Relative to EPSH } \\
\hline \multirow{15}{*}{60,000} & & & 1.05 & 1.03 & 1.03 & 1.03 & 1.02 & 1.01 & 1.00 & 1.00 & 1.00 & 1.00 & 1.00 & 1.00 \\
\hline & & 6 Offset & 1.03 & 1.00 & $0.9 \mathrm{~s}$ & 0.99 & 0.97 & 0.98 & 0.98 & 0.97 & 0.97 & 0.96 & 0.95 & 0.96 \\
\hline & 5,000 & RH 29-0.2\% Offset & 1.03 & 0.99 & 0.98 & 0.97 & 0.9 & 0.95 & 0.98 & 0.96 & 0.95 & 0.94 & 0.93 & 0.94 \\
\hline & & RH 29-0.5\% EUL & 1.02 & 0.98 & 0.97 & 0.96 & 0.9 & 0.93 & 0.97 & 0.96 & 0.94 & 0.93 & 0.92 & 0.92 \\
\hline & & CODE & 1.00 & 1.00 & 1.00 & 1.00 & 1.00 & 1.00 & 0.95 & 0.97 & 0.97 & 0.98 & 0.98 & 0.99 \\
\hline & \multirow{5}{*}{8,000} & EPSH & 1.07 & 1.08 & $1.0 €$ & 1.06 & 1.0 & 1.05 & 1.00 & 1.00 & 1.00 & 1.00 & 1.00 & 1.00 \\
\hline & & 29-0.1\% Offset & 1.07 & 1.06 & 1.03 & 1.03 & 1.0 & 1.01 & 1.00 & 0.98 & 0.97 & 0.97 & 0.96 & 0.96 \\
\hline & & $0.2 \%$ Offset & 1.07 & 1.05 & 1.02 & 1.01 & 0.95 & 0.98 & 1.00 & 0.97 & 0.96 & 0.95 & 0.94 & 0.94 \\
\hline & & $-0.5 \%$ EUL & 1.06 & 1.04 & 1.01 & 1.00 & 0.98 & 0.97 & 0.99 & 0.96 & 0.95 & 0.94 & 0.93 & 0.92 \\
\hline & & CODE & 1.00 & 1.00 & 1.00 & 1.00 & 1.0 & 1.00 & 0.93 & 0.92 & 0.94 & 0.95 & 0.95 & 0.96 \\
\hline & \multirow{5}{*}{12,000} & & 0.97 & 0.98 & 0.99 & 1.00 & 1.00 & 1.00 & 1.00 & 1.00 & 1.00 & 1.00 & 1.00 & 1.00 \\
\hline & & H 29-0.1\% Offset & 0.97 & 0.98 & 0.98 & 0.97 & 0.96 & 0.96 & 1.00 & 1.00 & 0.98 & 0.97 & 0.96 & 0.96 \\
\hline & & RH $29-0.2 \%$ Offset & 0.97 & 0.98 & 0.97 & 0.95 & 0.9 & 0.94 & 1.00 & 0.99 & 0.97 & 0.95 & 0.94 & 0.94 \\
\hline & & RH 29-0.5\% EUL & 0.97 & 0.97 & 0.96 & 0.94 & 0.93 & 0.93 & 0.99 & 0.99 & 0.97 & 0.94 & 0.93 & 0.93 \\
\hline & & CODE & 1.00 & 1.00 & 1.00 & 1.00 & 1.00 & 1.00 & 1.03 & 1.02 & 1.01 & 1.00 & 1.00 & 1.00 \\
\hline \multirow{15}{*}{80,000} & \multirow{5}{*}{5,000} & EPSH & 1.04 & 1.02 & 1.01 & 1.01 & 1.00 & 1.00 & 1.00 & 1.00 & 1.00 & 1.00 & 1.00 & 1.00 \\
\hline & & RH 29-0.35\% EUL & 1.03 & 1.00 & 0.95 & 0.98 & 0.97 & 0.96 & 0.99 & 0.98 & 0.98 & 0.97 & 0.97 & 0.96 \\
\hline & & RH 29-0.1\% Offset & 1.03 & 0.99 & 0.95 & 0.98 & 0.9 & 0.96 & 0.99 & 0.97 & 0.97 & 0.96 & 0.96 & 0.96 \\
\hline & & RH 29-0.2\% Offset & 1.02 & 0.98 & 0.97 & 0.96 & 0.9 & 0.93 & 0.98 & 0.96 & 0.96 & 0.95 & 0.94 & 0.93 \\
\hline & & & 1.00 & 1.00 & 1.00 & 1.00 & 1.00 & 1.00 & 0.96 & 0.98 & 0.99 & 0.99 & 1.00 & 1.00 \\
\hline & \multirow{5}{*}{8,000} & EPSH & 1.07 & 1.07 & 1.06 & 1.05 & 1.0 & 1.03 & 1.00 & 1.00 & 1.00 & 1.00 & 1.00 & 1.00 \\
\hline & & H 29-0.35\% EUL & 1.06 & 1.07 & 1.0 & 1.03 & 1.02 & 1.00 & 1.00 & 0.99 & 0.98 & 0.98 & 0.98 & 0.97 \\
\hline & & RH 29-0.1\% Offset & 1.06 & 1.06 & 1.02 & 1.02 & 1.0 & 0.99 & 0.99 & 0.99 & 0.98 & 0.97 & 0.97 & 0.96 \\
\hline & & RH 29-0.2\% Offset & 1.06 & 1.06 & 1.02 & 1.00 & 0.95 & 0.97 & 0.99 & 0.99 & 0.96 & 0.95 & 0.95 & 0.94 \\
\hline & & & 1.00 & 1.00 & 1.00 & 1.00 & 1.00 & 1.00 & 0.94 & 0.93 & 0.94 & 0.95 & 0.96 & 0.97 \\
\hline & \multirow{5}{*}{12,000} & EPSH & 0.97 & 0.98 & 0.95 & 0.99 & 1.00 & 0.98 & 1.00 & 1.00 & 1.00 & 1.00 & 1.00 & 1.00 \\
\hline & & RH 29-0.35\% EUL & 0.97 & 0.97 & 0.98 & 0.97 & 0.96 & 0.96 & 1.00 & 0.99 & 0.99 & 0.98 & 0.97 & 0.97 \\
\hline & & RH 29-0.1\% Offset & 0.97 & 0.97 & 0.98 & 0.97 & 0.9 & 0.95 & 1.00 & 0.99 & 0.99 & 0.98 & 0.96 & 0.97 \\
\hline & & RH 29-0.2\% Offset & 0.97 & 0.97 & 0.97 & 0.96 & 0.9 & 0.93 & 1.00 & 0.99 & 0.99 & 0.96 & 0.95 & 0.95 \\
\hline & & CODE & 1.00 & 1.00 & 1.00 & 1.00 & 1.0 & 1.00 & 1.03 & 1.02 & 1.01 & 1.01 & 1.00 & 1.02 \\
\hline
\end{tabular}

Note: $1000 \mathrm{psi}=6.895 \mathrm{MPa}$

Table A.4-Summary of results for rectangular column sections $(\gamma=\mathbf{0 . 6})$

\begin{tabular}{|c|c|c|c|c|c|c|}
\hline \multirow{3}{*}{$f_{y}$, psi } & \multirow{3}{*}{$f_{c}^{y}, \mathbf{p s i}$} & \multirow{3}{*}{$\begin{array}{l}\text { Reinforcement } \\
\text { Stress-Strain } \\
\text { Relationship }\end{array}$} & \multicolumn{2}{|c|}{$\begin{array}{c}\text { Longitudinal Reinforcement } \\
\text { Ratio, } \rho_{g}\end{array}$} & \multicolumn{2}{|c|}{$\begin{array}{c}\text { Longitudinal Reinforcement } \\
\text { Ratio, } \rho_{g}\end{array}$} \\
\hline & & & $1 \%$ & $2 \%$ & $1 \%$ & $2 \%$ \\
\hline & & & \multicolumn{2}{|c|}{$\begin{array}{c}\text { Strength Ratio Relative to } \\
\text { CODE }\end{array}$} & \multicolumn{2}{|c|}{$\begin{array}{c}\text { Strength Ratio Relative to } \\
\text { EPSH }\end{array}$} \\
\hline 60,000 & 5,000 & $\begin{array}{c}\text { EPSH } \\
\text { RH 29-0.1\% Offset } \\
\text { RH 29-0.2\% Offset } \\
\text { RH 29-0.5\% EUL } \\
\text { CODE }\end{array}$ & $\begin{array}{l}1.05 \\
1.05 \\
1.05 \\
1.04 \\
1.00\end{array}$ & $\begin{array}{l}1.04 \\
1.02 \\
1.01 \\
1.00 \\
1.00\end{array}$ & $\begin{array}{l}1.00 \\
1.00 \\
1.00 \\
0.99 \\
0.95\end{array}$ & $\begin{array}{l}1.00 \\
0.98 \\
0.97 \\
0.96 \\
0.96\end{array}$ \\
\hline 80,000 & 5,000 & $\begin{array}{c}\text { EPSH } \\
\text { RH 29-0.35\% EUL } \\
\text { RH 29-0.1\% Offset } \\
\text { RH 29-0.2\% Offset } \\
\text { CODE }\end{array}$ & $\begin{array}{l}1.06 \\
1.06 \\
1.06 \\
1.06 \\
1.00\end{array}$ & $\begin{array}{l}1.04 \\
1.04 \\
1.04 \\
1.03 \\
1.00\end{array}$ & $\begin{array}{l}1.00 \\
1.00 \\
1.00 \\
1.00 \\
0.95\end{array}$ & $\begin{array}{l}1.00 \\
1.00 \\
1.00 \\
0.99 \\
0.96\end{array}$ \\
\hline
\end{tabular}

Note: $1000 \mathrm{psi}=6.895 \mathrm{MPa}$ 


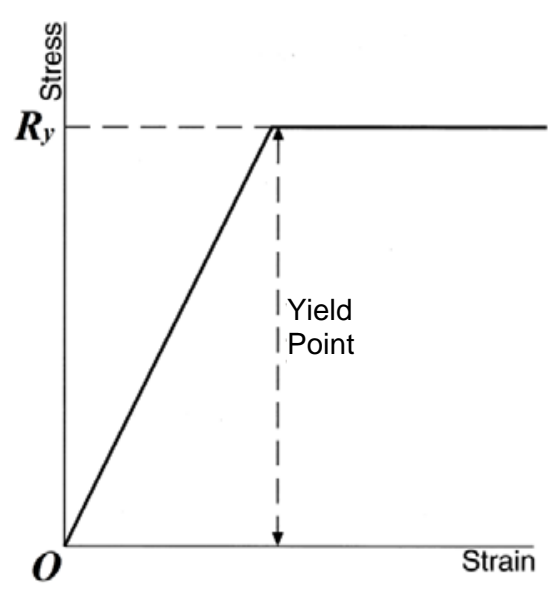

(a) Yield Point Method

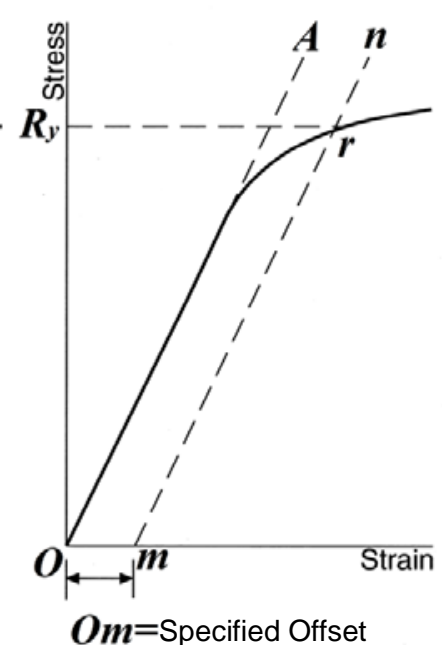

(b) Offset Method

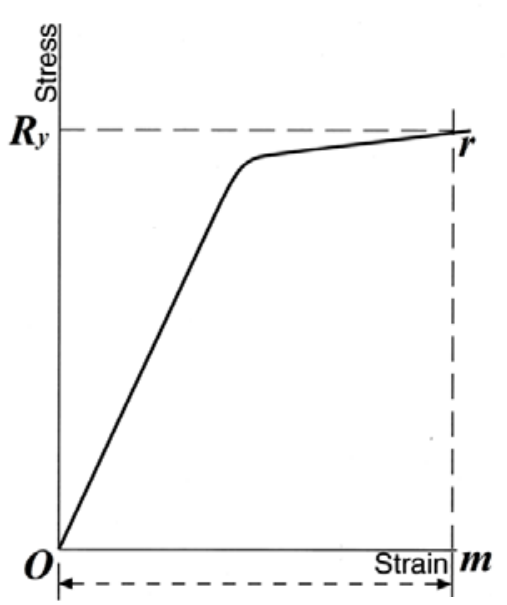

$\boldsymbol{O} \boldsymbol{m}=$ Specified Extension Under Load

(c) Extension Under Load Method

Fig. 1-Stress-strain diagrams showing methods of yield strength determination.

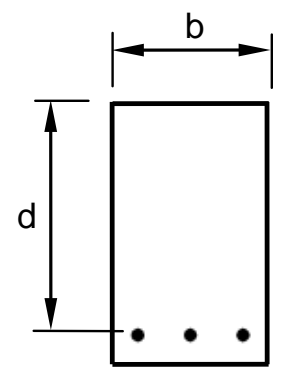

(a)

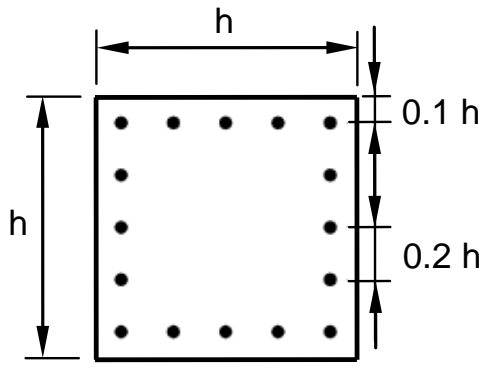

(b)

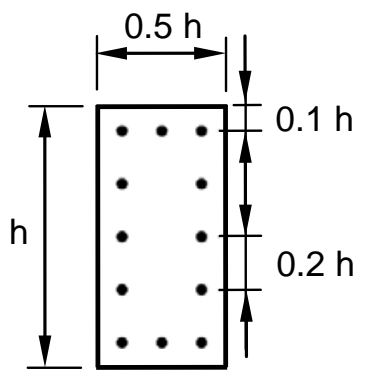

(c)

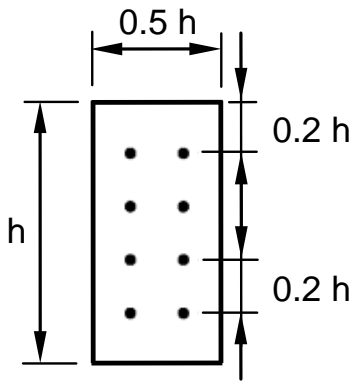

(d)

Fig. 2-Cross sections of members used in analyses.(a) Beam, (b) square column with $\gamma=0.8$, (c) rectangular column with $\gamma=0.8$, and (d) rectangular column with $\gamma=0.60$. 


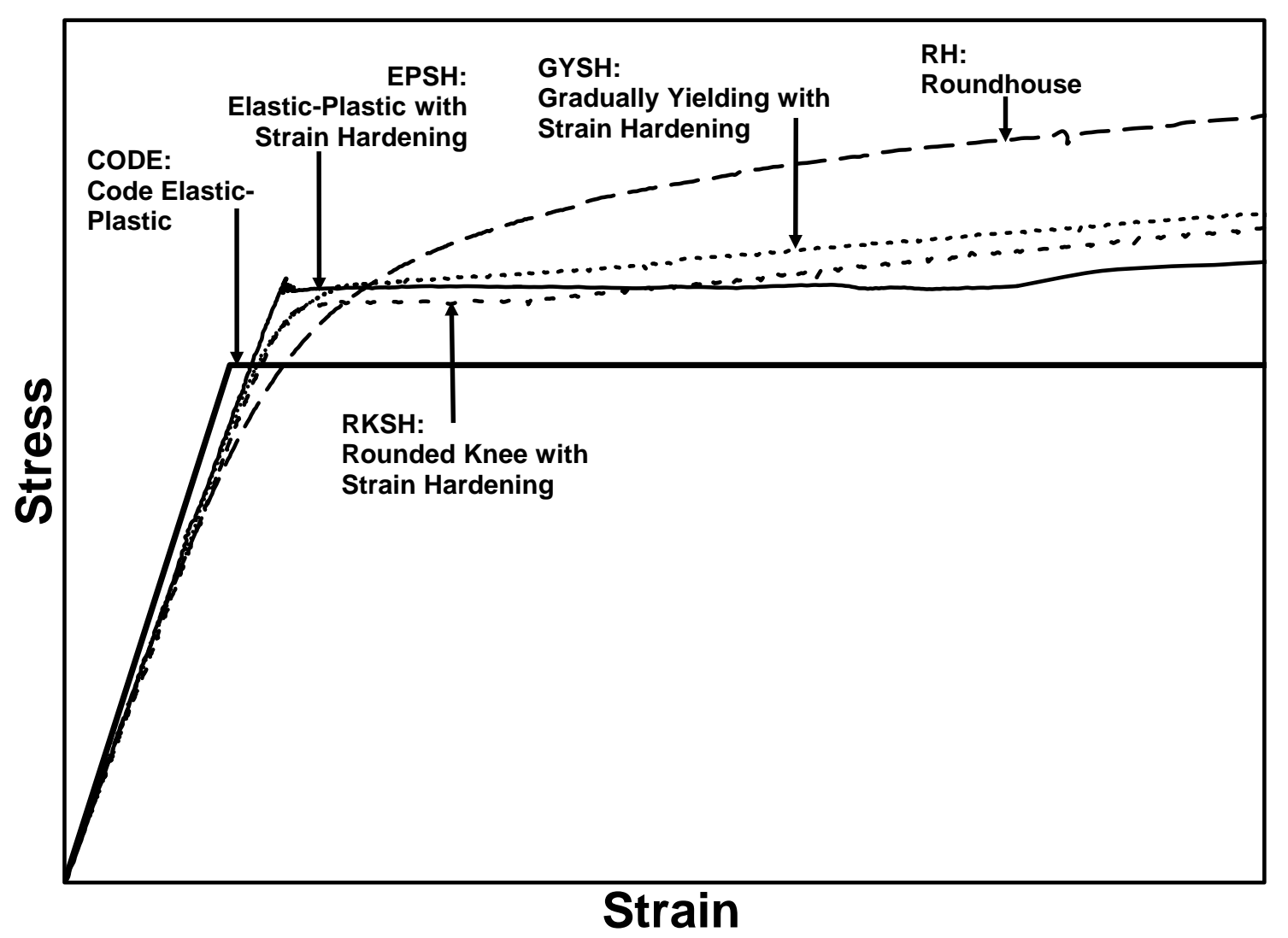

Fig. 3-Representative actual reinforcing steel stress-strain curves, illustrating various relationship characterization categories. 


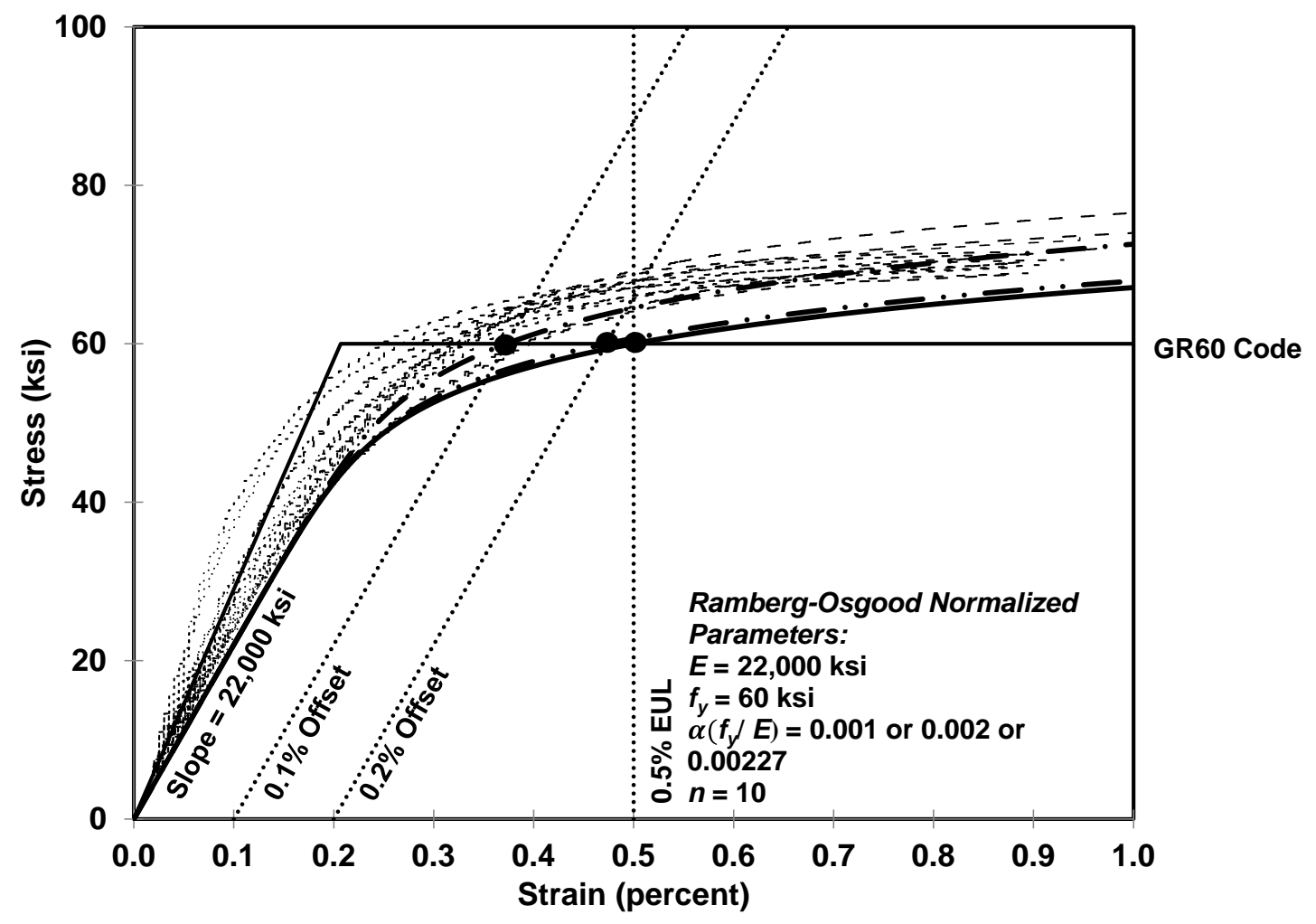

Fig. 4-Example of representative actual stress-strain curves (lighter-weight lines) and resulting normalized stress-strain relationships (heavy-weight lines) [Grade 60 (420) coiled bar reinforcement]. Note: $1 \mathrm{ksi}=6.895 \mathrm{MPa}$. 


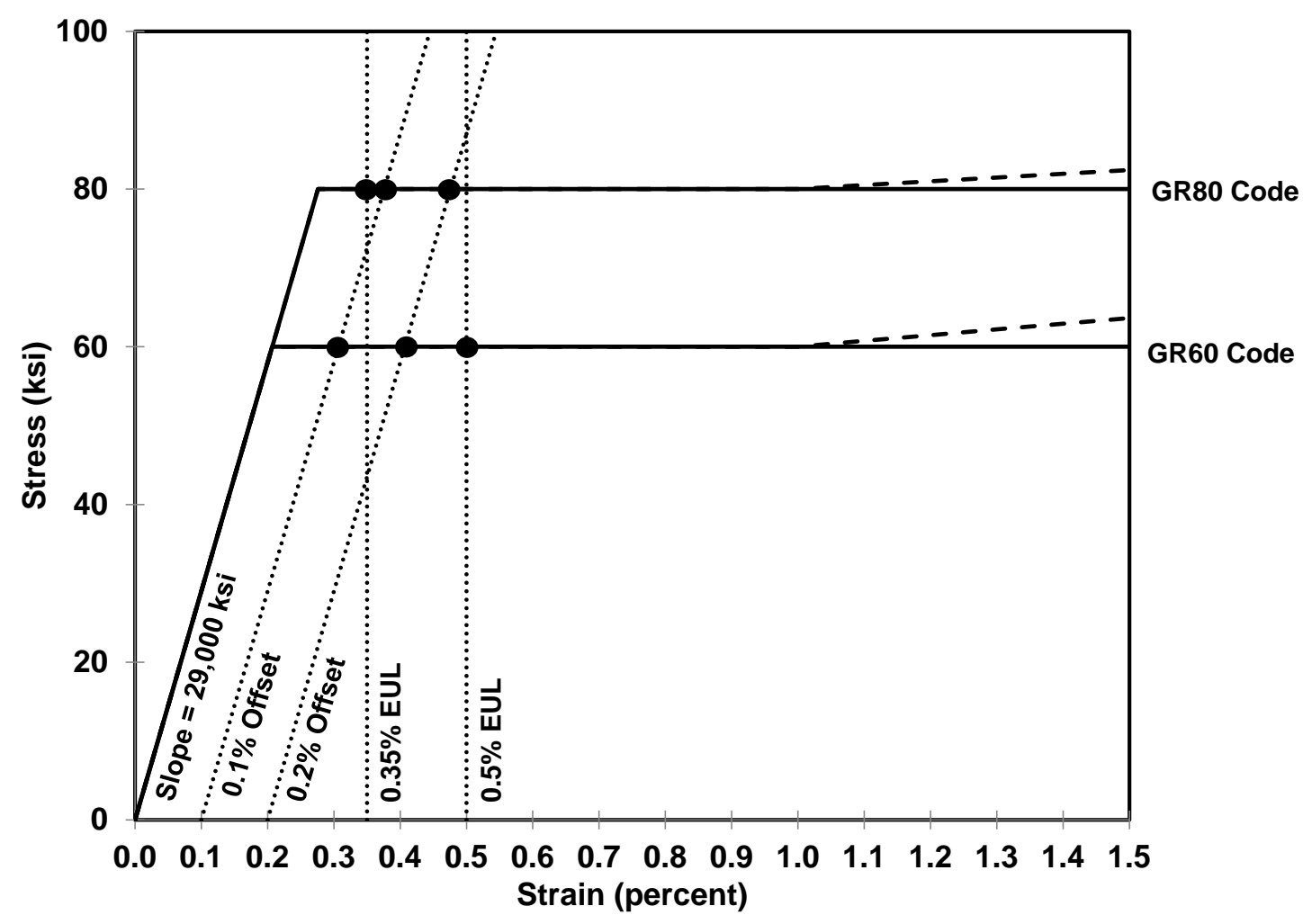

Fig. 5-Normalized CODE specified (solid lines) and EPSH (dashed lines) stress-strain relationships [Grades 60 and 80 (420 and 550)]. Note: $1 \mathrm{ksi}=6.895 \mathrm{MPa}$. 


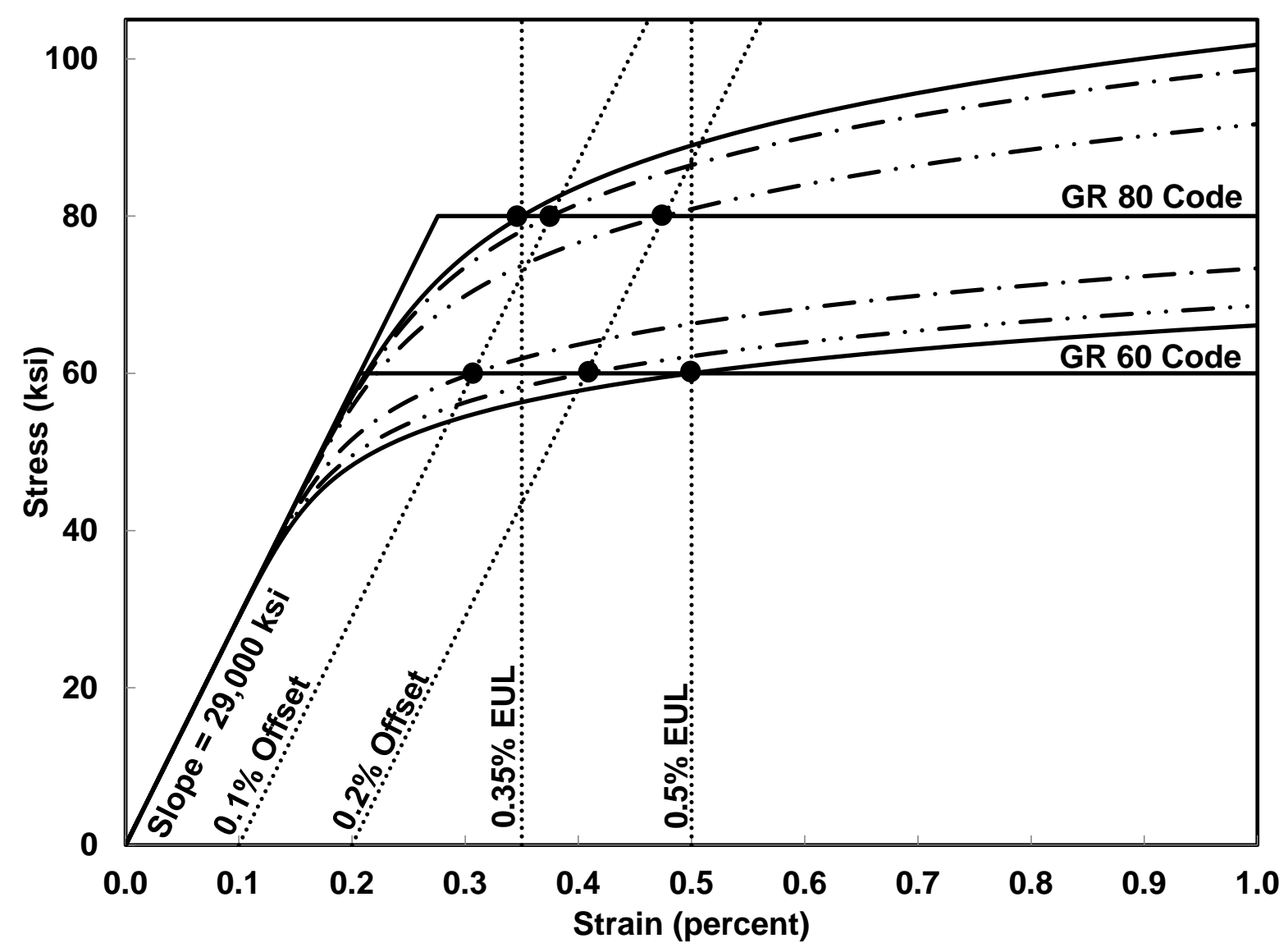

Fig. 6-Normalized stress-strain relationships for RH 29 curves [Grade 60 (420) 0.1\% and 0.2\% offset and 0.5\% EUL and Grade 80 (550) 0.1\% and 0.2\% offset and 0.35\% EUL]. Note: $1 \mathrm{ksi}=$ $6.895 \mathrm{MPa}$. 


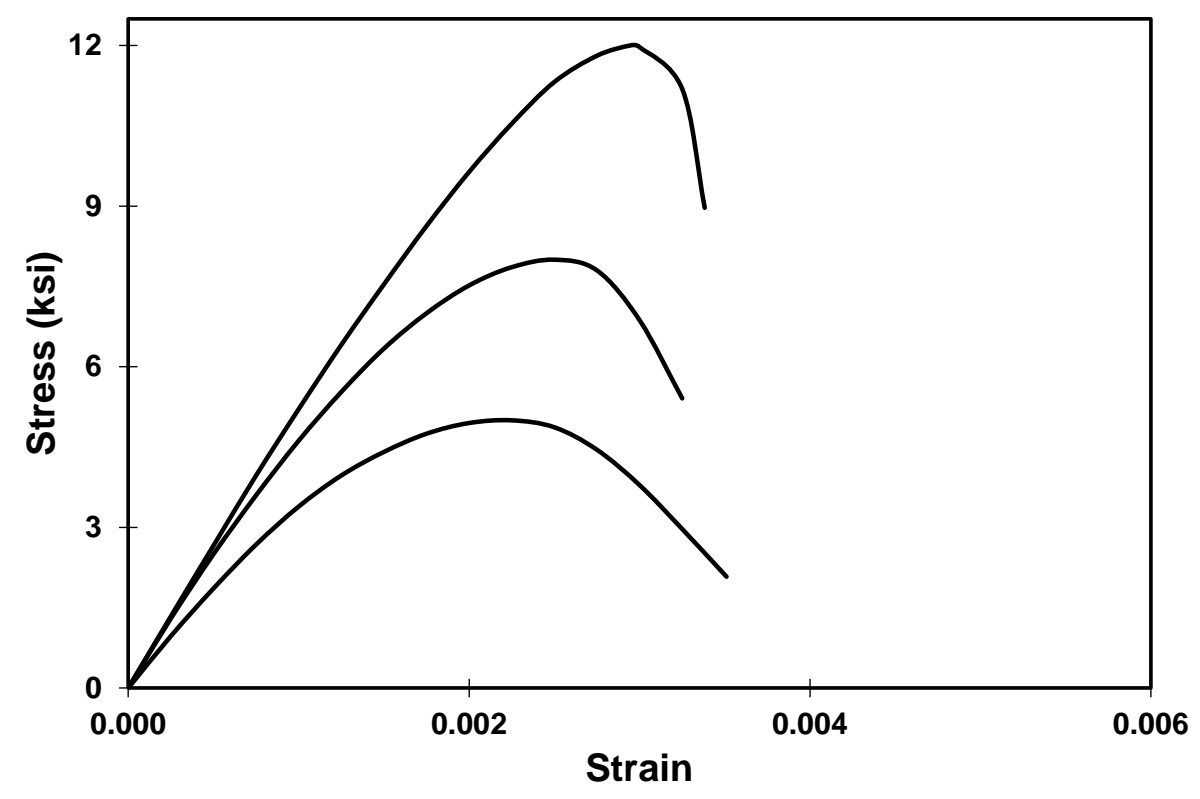

Fig. 7-Concrete stress-strain curves used for analyses for $\mathrm{f}_{\mathrm{c}}^{\prime}=5,000,8,000$, and 12,000 psi. Note: $1000 \mathrm{psi}=1 \mathrm{ksi}=6.895 \mathrm{MPa}$. 


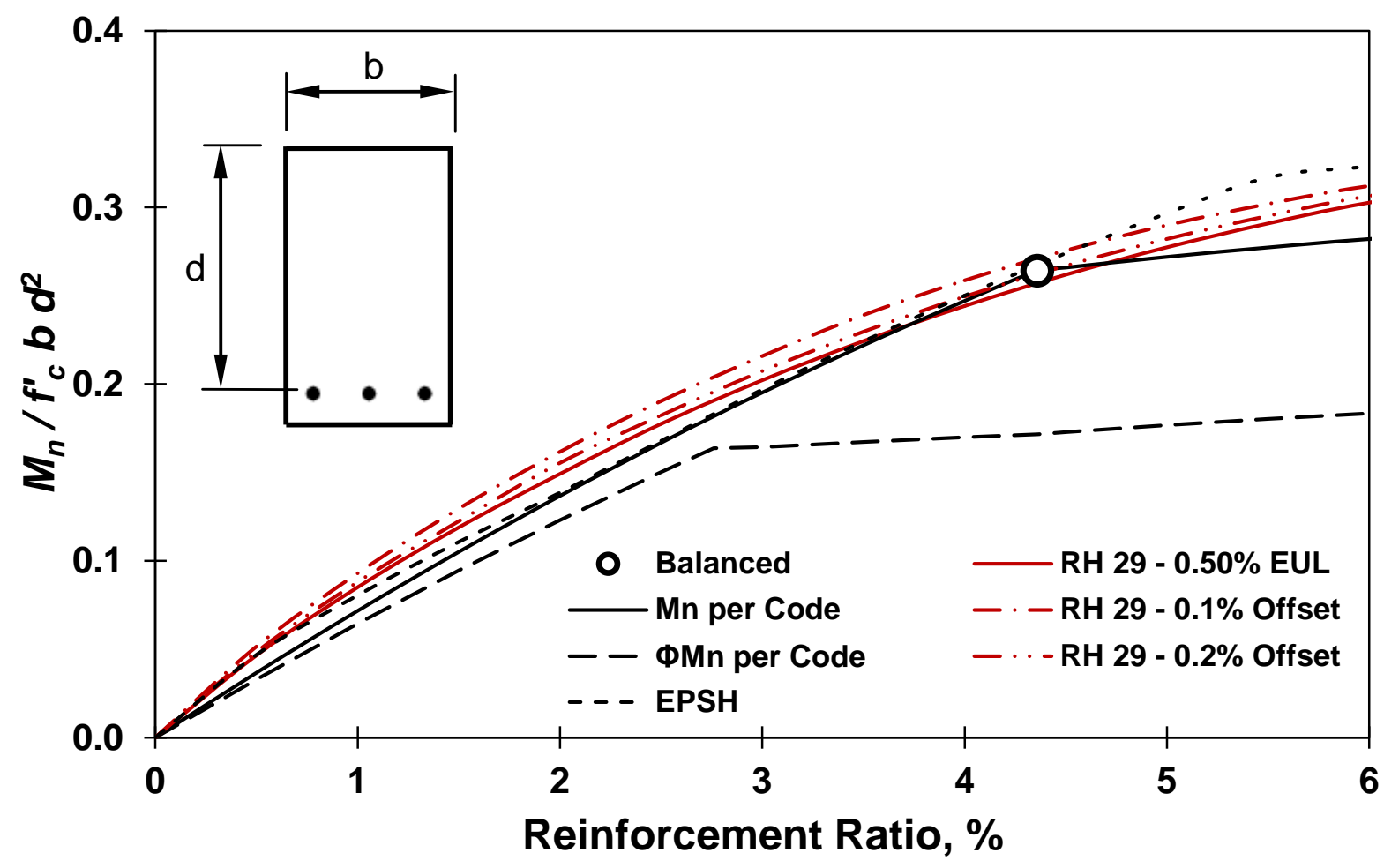

Fig. 8-Representative flexural strength vs. reinforcement ratios for beams ( $\mathrm{f}_{\mathrm{c}}^{\prime}=8,000$ psi and $\mathrm{f}_{\mathrm{y}}=60,000$ psi). Note: $1000 \mathrm{psi}=6.895 \mathrm{MPa}$. 


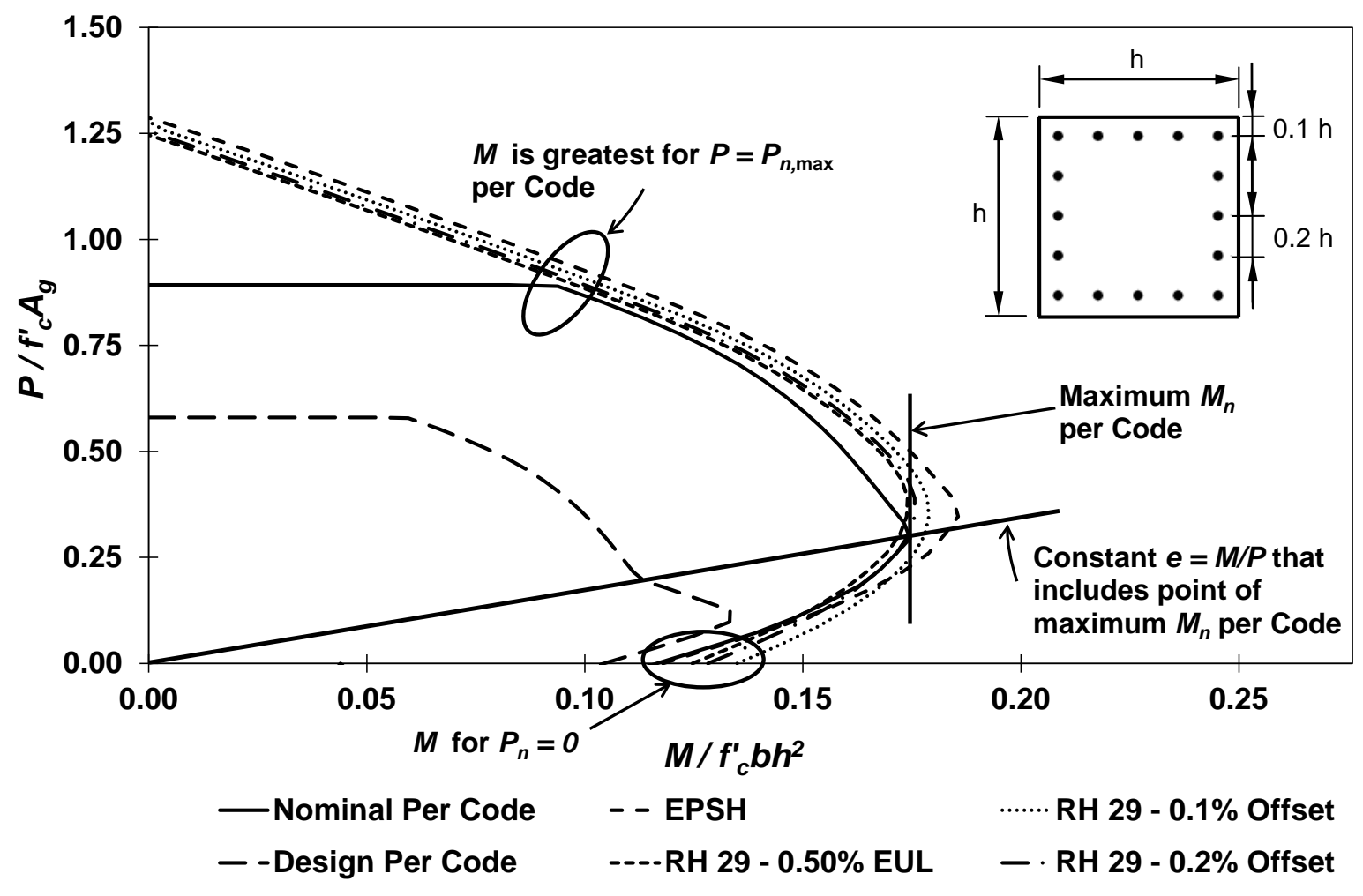

Fig. 9- Representative column axial load-bending moment interaction diagram (square column with $\mathrm{f}_{\mathrm{c}}^{\prime}=8,000 \mathrm{psi}, \mathrm{f}_{\mathrm{y}}=60,000 \mathrm{psi}$, and $\rho_{\mathrm{g}}=4$ percent) illustrating where relative strengths are evaluated. Note: 1000 psi $=6.895 \mathrm{MPa}$. 